\title{
Aerosol analysis and forecast in the European Centre for Medium-Range Weather Forecasts Integrated Forecast System: Forward modeling
}

\author{
J.-J. Morcrette, ${ }^{1}$ O. Boucher, ${ }^{2}$ L. Jones, ${ }^{1}$ D. Salmond, ${ }^{1}$ P. Bechtold, ${ }^{1}$ A. Beljaars, ${ }^{1}$ \\ A. Benedetti, ${ }^{1}$ A. Bonet, ${ }^{1}$ J. W. Kaiser, ${ }^{1}$ M. Razinger, ${ }^{1}$ M. Schulz, ${ }^{3}$ S. Serrar, ${ }^{1}$ \\ A. J. Simmons, ${ }^{1}$ M. Sofiev, ${ }^{4}$ M. Suttie, ${ }^{1}$ A. M. Tompkins, ${ }^{1,5}$ and A. Untch ${ }^{1}$ \\ Received 2 October 2008; revised 9 January 2009; accepted 21 January 2009; published 25 March 2009.
}

[1] This paper presents the aerosol modeling now part of the ECMWF Integrated

Forecasting System (IFS). It includes new prognostic variables for the mass of sea salt, dust, organic matter and black carbon, and sulphate aerosols, interactive with both the dynamics and the physics of the model. It details the various parameterizations used in the IFS to account for the presence of tropospheric aerosols. Details are given of the various formulations and data sets for the sources of the different aerosols and of the parameterizations describing their sinks. Comparisons of monthly mean and daily aerosol quantities like optical depths against satellite and surface observations are presented. The capability of the forecast model to simulate aerosol events is illustrated through

comparisons of dust plume events. The ECMWF IFS provides a good description of the horizontal distribution and temporal variability of the main aerosol types. The forecastonly model described here generally gives the total aerosol optical depth within 0.12 of the relevant observations and can therefore provide the background trajectory information for the aerosol assimilation system described in part 2 of this paper.

Citation: Morcrette, J.-J., et al. (2009), Aerosol analysis and forecast in the European Centre for Medium-Range Weather Forecasts Integrated Forecast System: Forward modeling, J. Geophys. Res., 114, D06206, doi:10.1029/2008JD011235.

\section{Introduction}

[2] In April 1989, the ECMWF model was the first operational forecast model to include the effects of aerosols as part of its radiation transfer calculations (from the initial work of Tanré et al. [1984] in a climate version of the model). Since then, a revised aerosol climatology [Tegen et al., 1997] was introduced in October 2003, and various studies [Tompkins et al., 2005; Rodwell, 2005] showed the positive impact of this change on various aspects of the model, sometimes far from the location of the main change in aerosol optical thickness.

[3] As part of the project Global and regional Earthsystem Monitoring using Satellite and in situ data (GEMS) [Hollingsworth et al., 2008], the European Centre for Medium-Range Weather Forecasts (ECMWF) is developing its assimilation system to include observations pertaining to greenhouse gases, reactive gases and aerosols. For the

\footnotetext{
${ }^{1}$ European Centre for Medium-Range Weather Forecasts, Reading, UK.

${ }^{2}$ Met Office, Exeter, UK.

${ }^{3}$ Laboratoire des Sciences du Climat et de 1'Environnement, Gif-surYvette, France.

${ }^{4}$ Air Quality Research, Finnish Meteorological Institute, Helsinki, Finland.

${ }^{5}$ Now at Earth System Physics, International Centre for Theoretical Physics, Trieste, Italy.

Copyright 2009 by the American Geophysical Union. 0148-0227/09/2008JD011235\$09.00
}

computation of the trajectory forecast used in the assimilation, the Integrated Forecast System (IFS) has been extended to include a number of tracers, which are advected by the model dynamics and interact with the various physical processes. With respect to the aerosols, sources have thus been added to the model, and a representation of the aerosol physical processes (namely the interactions of the aerosols with the vertical diffusion and the convection, plus the sedimentation, dry deposition and wet deposition by largescale and convective precipitation) are now part of the package of physical parameterizations of the ECMWF IFS model. A prognostic representation of aerosols is a feature of numerous climate models (see Schulz et al. [2006], Textor et al. [2006, 2007], and Kinne et al. [2006] for reviews of how various aspects of aerosol physics are represented in recent general circulation models). However, it is more of a novelty in global weather forecast models, given the requirements on the assimilation system to deal properly with the aerosol-relevant observations and the time constraint for producing an analysis and subsequent forecast in a near-real-time environment. As part of the GEMS project, aerosol-related observations (i.e., either aerosol optical depth retrievals or more directly, aerosol-sensitive radiances) will be assimilated together with all the other observations in a fully interactive way (A. Benedetti et al., Aerosol analysis and forecast in the ECMWF Integrated Forecast System: 2. Data assimilation, submitted to Journal of Geophysical Research, 2009). 
[4] Apart from the real-time analyses including aerosols to provide for example initial conditions to regional air quality models, reanalyses of meteorological and aerosol data over several decades with a fixed analysis-forecast system including aerosols could provide information on how aerosols are linked to a changing climate. Another more immediate objective is the provision of a combined meteorological and aerosol forecast. In all cases, the present state-of-the-art analysis system used at ECMWF includes a four-dimensional variational assimilation including not only the direct version of the model code, but also the (tangentlinear and) adjoint versions of the code, required to propagate the analysis increments (the differences between the observations and their model counterparts) back to the initial conditions of the forecast [Rabier et al., 2000; Klinker et al., 2000]. The same requirement for direct, tangent-linear and adjoint versions also applies to the computer description of the aerosol processes. The introduction of prognostic aerosol variables increases significantly the cost of the forecast model (a factor of 2 for the version of the ECMWF IFS used in this study). Therefore, a certain level of simplification has to be considered when accepting an existing parameterization from the literature or designing a new one for the model. In this respect, the emphasis is somewhat different from that of the representation of aerosols in a general circulation model used for climate studies where aerosol processes may have a sophisticated representation in order to be able to handle various sensitivity and feedback studies. Here, the forecast model including aerosols will be used at relatively high resolution, both horizontally and vertically, to provide information on the aerosol loading over the time scale of a few hours to a few days. In consequence, the dynamical transport becomes of primary importance in such forecasts, including the possibility of backward trajectories to determine, for example, the origin of the aerosols over a given point at a given time. It is therefore important not only to simulate the aerosol loading (and in the future, aerosol radiative forcing and possible impact of aerosols on clouds) on a monthly mean time scale, but it is even more important that the correct monthly means are obtained from an accurate representation of the short-term variability of the aerosol distributions as objective scores describing the quality of an aerosol forecast will depend mainly on how successful the model is at capturing this day-to-day temporal variability.

[5] Section 2 gives an overview of how the aerosols are introduced in the ECMWF IFS, with information on the parameterizations and data sets used for the aerosol sources in the ECMWF aerosol model. Section 3 focuses on the representation of the sink terms. In section 4, comparisons of monthly mean optical depths at $550 \mathrm{~nm}$ against equivalent quantities derived from satellite observations (MODerate resolution Imaging Spectrometer, MODIS and Multi-angle Imaging SpectroRadiometer, MISR) are first presented. Then the representation of the day-to-day variability of the modeled aerosols is assessed through comparisons with surface measurements at AERONET (AErosol RObotic NETwork) [Holben et al., 1998] sites. Finally, an example of a forecast of meteorological events when a heavy aerosol load was prevalent is presented, together with some preliminary comparison of aerosol vertical distribution with the cloud-aerosol mask derived from CALIPSO/
CloudSat measurements, and model aerosol optical depths at wavelengths other than $550 \mathrm{~nm}$. Conclusion and perspectives are given in section 5 .

\section{Model Environment and Aerosol Sources}

[6] In the following, all mentions of the ECMWF model refer to the cycle $32 \mathrm{R} 2$ version of the library, operational from 5 June 2007 to 5 November 2007, set up for a $T_{L} 159$ horizontal resolution (a grid of $\left[1.125^{\circ}\right]^{2}$ in the tropics) and either 60 vertical levels over the period December 2002 to May 2005 or 91 levels for the near-real-time simulations started on 15 May 2007. Within the model, tracers (e.g., aerosols in this study) are advected in a way consistent with the rest of the dynamics. Over the past 15 years, a number of transport and climate models have included a representation of aerosol processes and an abundant literature exists on most details of their parameterization (see Schulz et al. [2006] and Textor et al. [2006, 2007] for an overview and a recent list of references). Here, we only reference the main approaches for these various parameterizations and only detail those being introduced within the ECMWF model. Since 2005, developments in the ECMWF physical package have allowed the vertical diffusion and the mass-flux convection schemes to account explicitly for tracers, including aerosols. The wet and dry deposition schemes were directly adapted from the LOA/LMD-Z model [Reddy et al., 2005], whereas the sedimentation of aerosols follows closely what has been done for ice particles by Tompkins [2005]. Details on the sources and other aerosol-related physical processes are given below. A diagram showing how the ECMWF IFS physical package has been updated to deal with the prognostic aerosols is given in Figure 1.

\subsection{Model Environment}

[7] The initial package of ECMWF physical parameterizations dedicated to aerosol processes mainly follows the aerosol treatment in the LOA/LMD-Z model [Boucher et al., 2002; Reddy et al., 2005]. Five types of tropospheric aerosols are considered: sea salt, dust, organic and black carbon, and sulphate aerosols. A prognostic representation of the stratospheric aerosols is not included here, as the period 2003-2004 considered for the initial model development was almost devoid of any sizeable amount of stratospheric aerosols (at least, from a radiative point of view). Similarly, the emission of aerosols by volcanoes is not present in the following results. Both types of aerosols will be considered in a later stage of the GEMS-Aerosol project.

[8] For all tropospheric aerosols, sources are defined, the sedimentation of all particles, and the wet and dry deposition processes are represented. In addition, the transfer from hygrophobic to hygrophilic, specific to organic matter (OM) and black carbon (BC) aerosols, is also included.

[9] A bin representation is used in this study to include prognostic aerosols of natural origin (taken to mean sea-salt SS and dust DU). From the start of the GEMS-Aerosols project, it had been decided to allow the maximum flexibility regarding the limits of the bins for the sea-salt and dust aerosols. In the following, the sea-salt aerosols are tentatively represented by 3 bins, with limits at $0.03,0.5,5$ and 20 microns. Similarly, the desert dust aerosols are 
Development of a prognostic aerosol package for the ECMWF forecast model

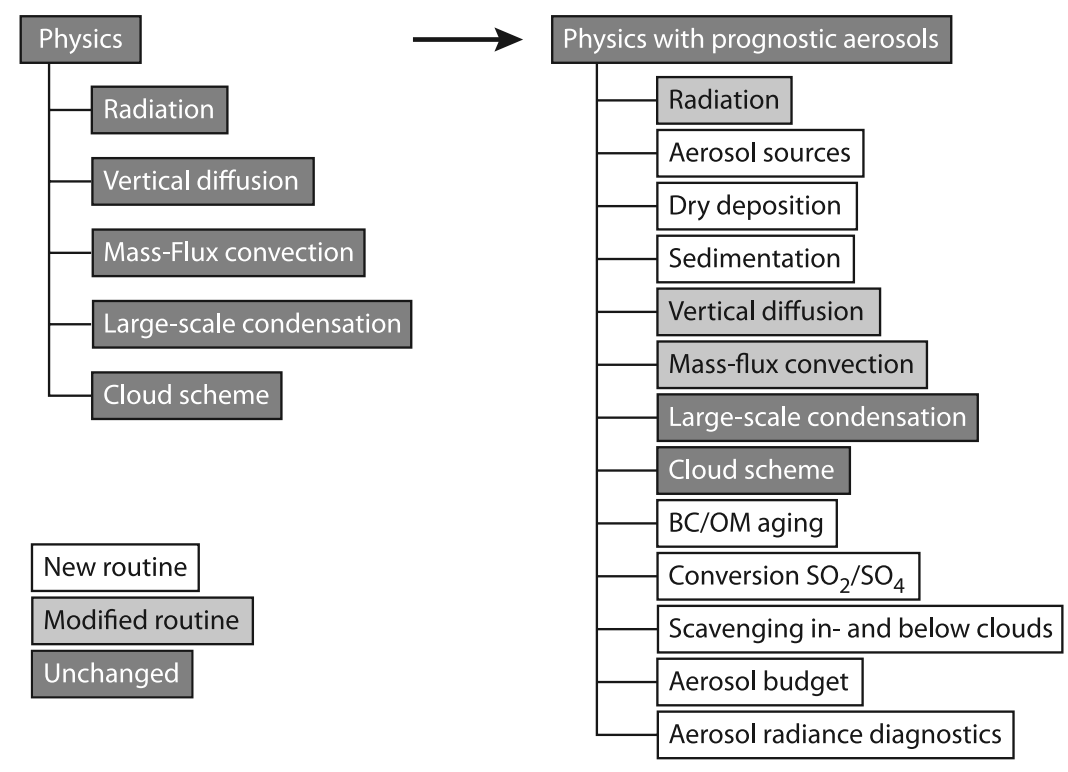

Figure 1. Comparison of calling sequence for the physics (left) without and (right) with routines for prognostic aerosols.

represented by 3 bins with limits at $0.03,0.55,0.9$, and 20 microns. The above limits are chosen so that roughly 10 , 20 and $70 \%$ of the total mass of each aerosol type are in the various bins.

[10] For organic matter and black carbon, two components, hygrophobic and hygrophilic, are considered. A very simplified representation of the sulphur cycle is included with only two variables, sulphur dioxide $\left(\mathrm{SO}_{2}\right)$ and sulphate $\left(\mathrm{SO}_{4}\right)$, this latter one in the particulate phase. Overall, a total of 12 new prognostic variables for the mass mixing ratio of the different components (bins or types) of the various aerosols are now used in the two-time-level semi-Lagrangian dynamics of the ECMWF IFS [Temperton et al., 2001].

\subsection{Aerosol Sources}

[11] In the ECMWF IFS, the two natural aerosols (SS and DU) have their sources linked to prognostic and diagnostic surface and near-surface model variables. In contrast, the anthropogenic aerosols (OM, $\mathrm{BC}$ and $\left.\mathrm{SO}_{4}\right)$ have their sources read from external data sets.

[12] Recently, the importance of accounting for gustiness in the surface wind used for diagnosing the surface flux of particles was stressed by Engelstaedter and Washington [2007]. However, in the following, we present results obtained for sea salt and dust surface flux formulations using plain 10-m wind. The 10-m wind for April 2003 is presented in Figure 2, separately over the ocean and continental surfaces.

\subsubsection{Sea Salt}

[13] Different approaches to sea-salt production are reviewed by Guelle et al. [2001] and a detailed description of the processes involved is given by Grini et al. [2002]. They include the generation of sea spray by wind stress on the ocean surface, either from air bubbles in the whitecaps, or at higher wind speeds, from spume drops torn directly from the wave crests [Smith et al., 1993].
[14] The vertical flux $F_{0}$ of sea-salt aerosols is parameterized from the $10-\mathrm{m}$ wind at the free ocean surface following Monahan et al. [1986],

$$
\frac{d F_{0}}{d r}=1.373 u_{10}^{3.41} r^{-3}\left(1+0.057 r^{1.05}\right) 10^{1.19 e^{-B^{2}}}
$$

where $B=(0.380-\ln r) / 0.650, r$ is the particle radius (in $\mu \mathrm{m})$ and $u_{10}$ the $10-\mathrm{m}$ wind speed (in $\mathrm{m} \mathrm{s}^{-1}$ ). The emission flux $F_{i}$ (in particles $\mathrm{m}^{-2} \mathrm{~s}^{-1}$ ) for a size bin $(i)$ is obtained by integrating (2) over the size range $\left(r_{i 1}\right.$ to $\left.r_{i 2}\right)$ in the bin to yield

$$
F_{i}\left(u_{10}\right)=a_{i} u_{10}^{3.41}
$$

A density of $2160 \mathrm{~kg} \mathrm{~m}^{-3}$ is assumed for dry particles. Seasalt production is calculated assuming an $80 \%$ relative humidity. At this relative humidity, the particle radius will be twice the dry radius [Fitzgerald, 1975], and the density used in the production is thus $1182 \mathrm{~kg} \mathrm{~m}^{-3}$. The number of particles produced is converted to mass according to

$$
M=\frac{4 \pi N \rho_{p} r^{3}}{3}
$$

where $M$ is the total mass produced in a model grid cell (kg), $N$ is the total number produced, $\rho_{p}$ is the particle density, and $r$ is the radius.

[15] Only the dry mass is added to the bin and transported. Thus no water is transported via the aerosols. Mass is not transferred between bins because of growth. However, wet density and radius are considered for all the size bins when dealing with dry deposition, sedimentation and radiation.

[16] Whereas the source function described above was initially tested in the IFS, in the following, the surface flux 

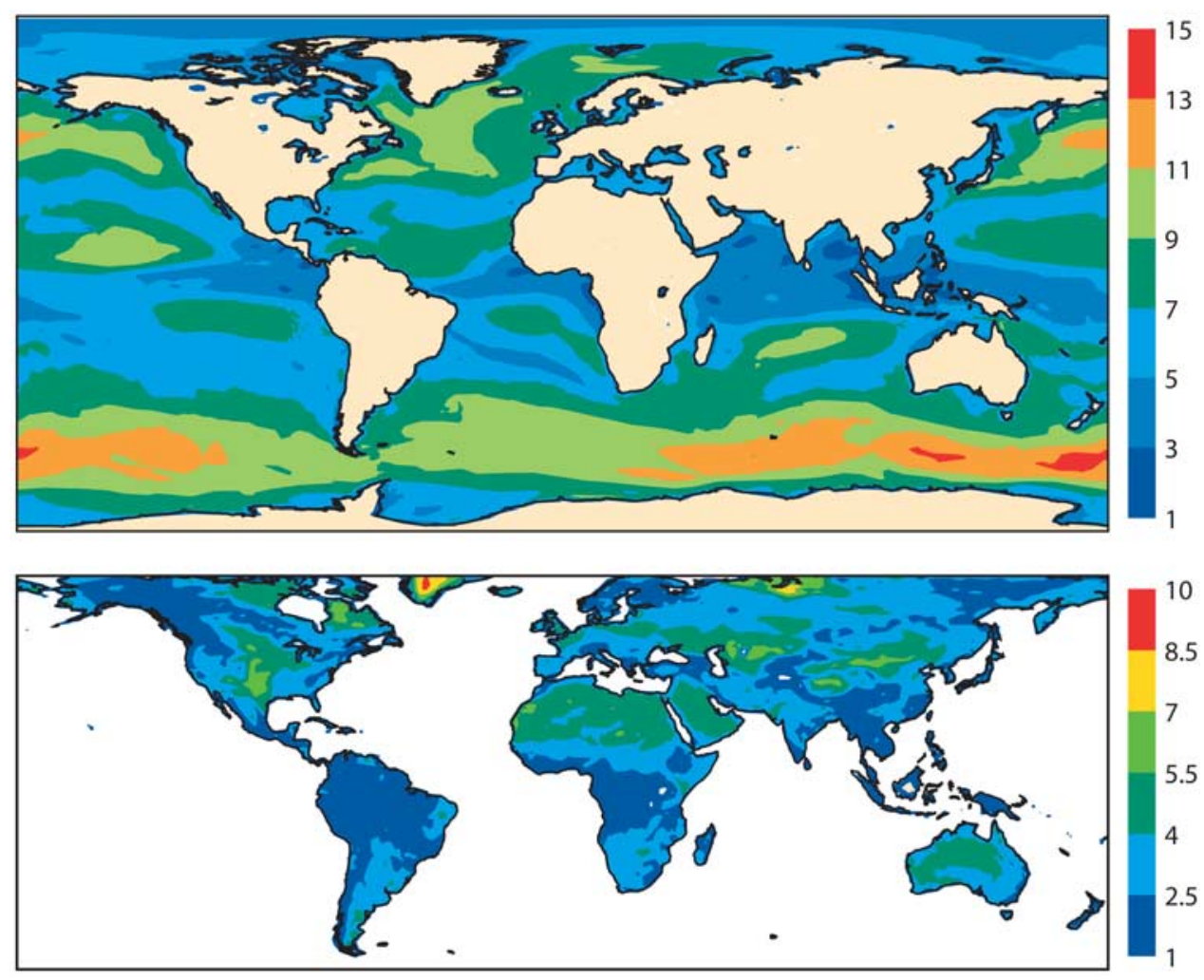

Figure 2. Wind speed at $10 \mathrm{~m}$ over (top) ocean and (bottom) land for April 2003 (in m s${ }^{-1}$ ).

of sea salt is diagnosed using a source function based on work by Guelle et al. [2001] and Schulz et al. [2004]. In this LSCE/ECMWF formulation, wet sea-salt mass fluxes at $80 \%$ relative humidity are integrated for the three size bins discussed above, merging work by Monahan et al. [1986] and Smith and Harrison [1998] between 2 and $4 \mu \mathrm{m}$. Similar source functions have been proposed by Vignati et al. [2001] and Grini et al. [2002]. All these studies suggest to combine different source functions if one is interested in a wider aerosol size range. Figure 3 presents the source of sea-salt aerosols from the ECMWF IFS formulation, averaged over April 2003, showing maximum emission over the Northern and Southern Hemisphere storm tracks.

\subsubsection{Dust}

[17] Dust mobilization is sensitive to a wide range of factors including soil composition, soil moisture, surface conditions and wind velocity. Dust uplift to the atmosphere is mainly initiated by saltation bombardment (sand blasting). Various parameterizations have been developed over the years to represent these processes [Gillette et al., 1980; Tegen and Fung, 1994; Ginoux et al., 2001]. Marticorena and Bergametti [1995] developed a sophisticated parameterization of this process, which requires detailed information on soil characteristics, which is not readily available in the ECMWF global model.

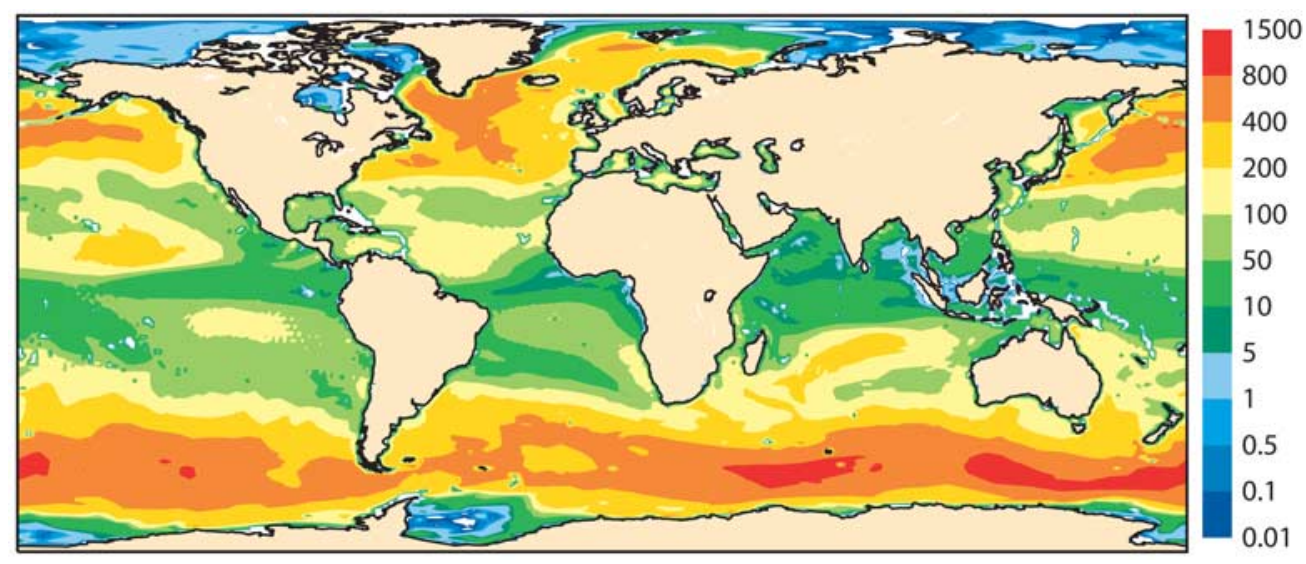

Figure 3. Source of sea-salt aerosols for April 2003 with the LSCE/ECMWF formulation (in units of $\left.\mathrm{g} \mathrm{m}^{-2} \mathrm{a}^{-1}\right)$. 
a

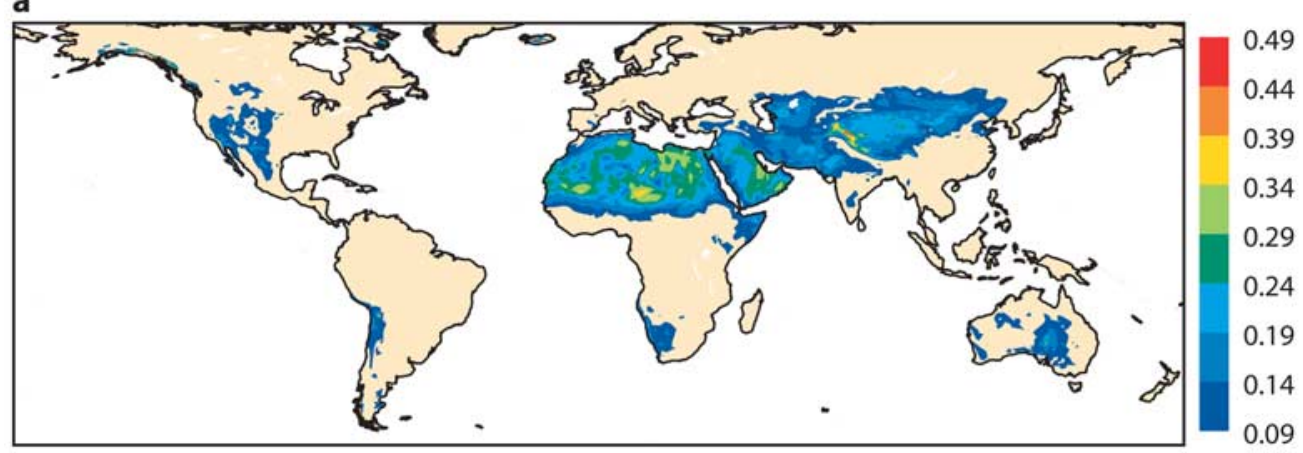

b

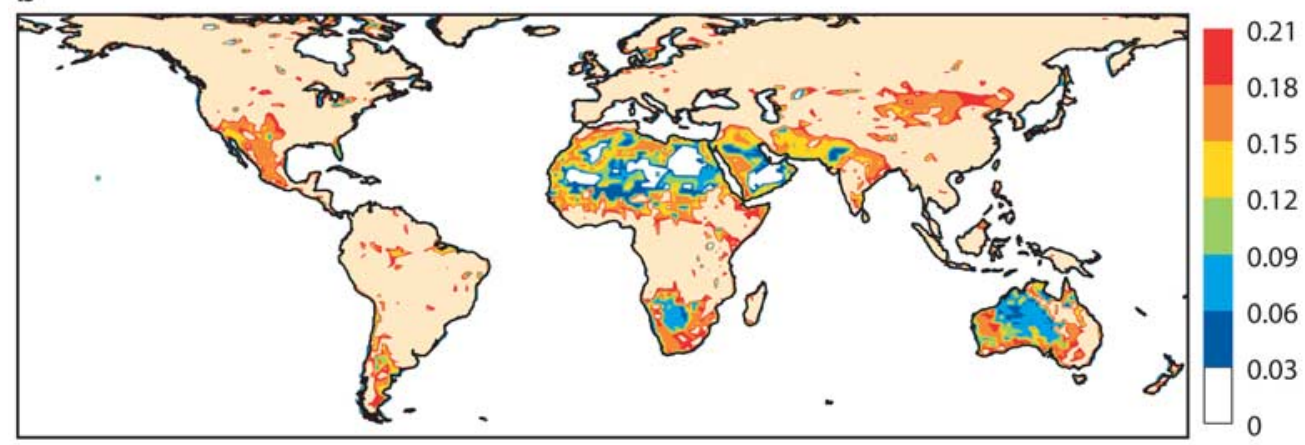

C

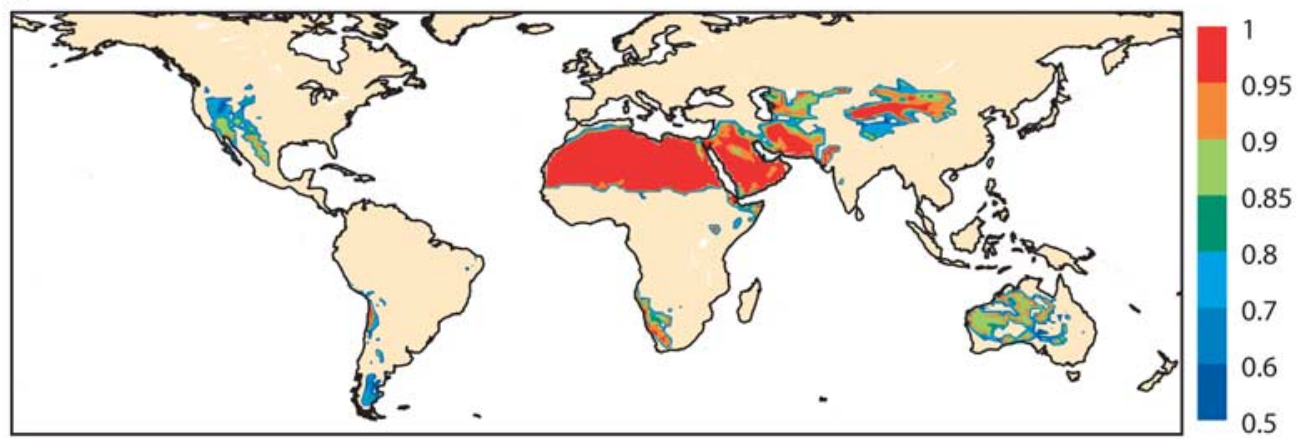

Figure 4. (a) Background albedo in the ultraviolet-visible part of the shortwave spectrum, for April 2003, from a snow-free climatology based on 2000-2004 observations. Only albedos with values between 0.09 and 0.54, assumed to be representative of light-colored soil and sparse vegetation, are plotted. (b) Soil moisture in the first layer of the ECMWF IFS model for April 2003. (c) Fraction of bare soil for April 2003.

[18] For the production of desert dust in the ECMWF model, a formulation of the source was implemented following Ginoux et al. [2001]. First, the areas likely to produce dust are diagnosed for snow-free land with at least $10 \%$ of bare soil, and the soil moisture below the wilting point (at which point, evaporation by soil and vegetation stops and dust might be more easily lifted). For these areas, the dust flux is a function of the surface wind

$$
F_{i}\left(u_{10}\right)=\left\{\begin{array}{lc}
S u_{10}^{2}\left(u_{10}-u_{t}\right) & \text { if } u_{10}>u_{t} \\
0 & \text { otherwise }
\end{array},\right.
$$

where $u_{t}$ is a lifting threshold speed depending on soil wetness and particle radius and $S$ is the source function $(S=$ $2 \times 10^{-11} \mathrm{~kg} \mathrm{~s}^{2} \mathrm{~m}^{-5}$ ). The main difference with the approach of Marticorena and Bergametti [1995] is that $S$, also called dust emission potential, is here independent of the soil morphology, and we rely on the $10-\mathrm{m}$ wind, vegetation cover, soil moisture, (absence of) snow cover provided by the model and the MODIS-derived UV-visible component of the land surface albedo (between 0.09 and 0.54 ) to diagnose which areas are likely to produce a flux of dust. Figure 4 presents the UV-visible albedo, moisture in the first soil layer, and the fraction of bare soil for April 2003. The corresponding sources of dust aerosols diagnosed with the formulation discussed above is shown in Figure 5.

\subsubsection{Organic Matter, Black Carbon, and Sulphate}

[19] Sources for the other aerosol types are taken from the GFED (Global Fire Emission Database), SPEW (Speciated Particulate Emission Wizard), EDGAR (Emission Database for Global Atmospheric Research) annual mean or monthly mean climatologies until more temporally resolved data are provided as part of the GEMS project. Overall, these data 


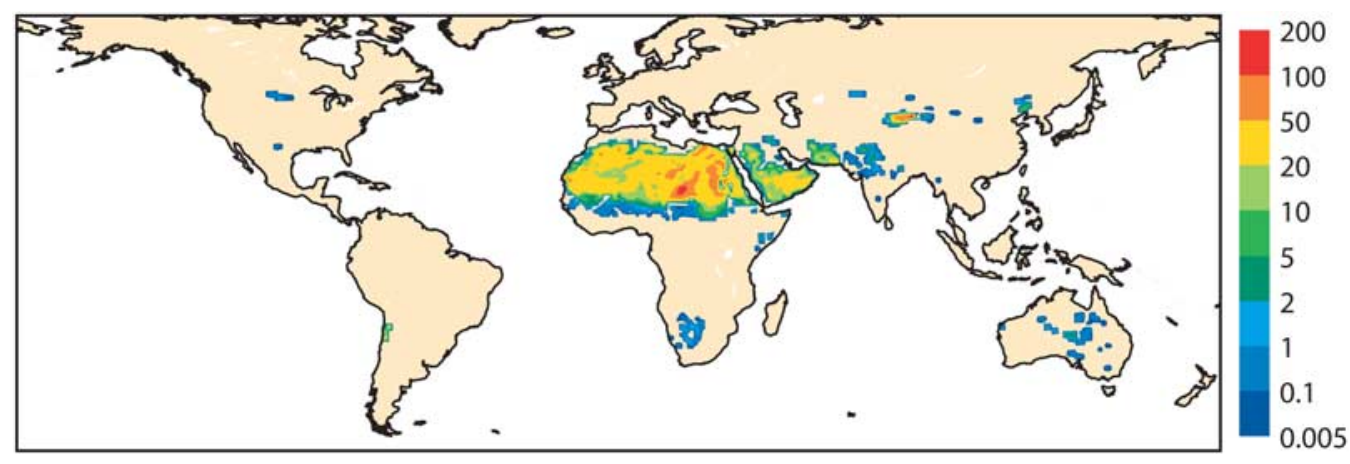

Figure 5. Source of dust aerosols for April 2003 (in units of $\mathrm{g} \mathrm{m}^{-2} \mathrm{a}^{-1}$ ).

sets include sources of organic and black carbon, and sulphate aerosols linked to fire emissions, both natural and anthropogenic, plus emissions from domestic, industrial, power generation, transport and shipping activities. More details on the sources of aerosols are given by Dentener et al. [2006]. The data sets used for the original model development were extracted from the AEROCOM (AEROsol Comparisons between Observations and Models) emission inventories. For the results presented in sections 4.1 to 4.4 , version 2 of the GFED data set, given as 8-day means for the emissions of organic and black carbon, and sulphate aerosols is used.

\section{Removal Processes}

[20] Several types of removal processes are considered, the dry deposition including the turbulent transfer to the surface and the gravitational settling, and the wet deposition including rainout (by large-scale and convective precipitation) and washout of aerosol particles in and below the clouds. The wet and dry deposition schemes are standard, whereas the sedimentation of aerosols follows closely what was recently introduced for the sedimentation of ice particles. Hygroscopic effects are also considered here.

\subsection{Dry Deposition}

[21] The turbulent transfer of particles at the surface is represented as a decrease in the emission flux represented through a deposition velocity $v_{d}$. A review of the knowledge on dry deposition, taking into account the surface type (ocean or land, vegetation type) is given by Wisely and Hicks [2000]. In these preliminary results, the dry deposition to the surface is accounted for through a decrease of the aerosol concentration in the lowermost model layer assuming a flux

$$
F_{D D}=C v_{d}
$$

where $C$ is the concentration in the first layer above the surface (in $\mathrm{g} \mathrm{m}^{-3}$ ), $v_{d}$ is the dry deposition velocity, simply function of the particle mode radius and surface type [see Reddy et al., 2005, Table 1]. More sophisticated representations would make $v_{d}$ depend on the aerodynamic resistance $r_{a}$ and the resistance in the quasi-laminar sublayer $r_{b}$, linking it to either the vegetation or the wave characteristics.

\subsection{Sedimentation}

[22] For the larger aerosols, the most efficient removal process is the gravitational settling (sedimentation). The change in concentration follows the approach developed by Tompkins [2005] for the sedimentation of ice. For a concentration $C$, including a flux form term for transport at a velocity $v_{s}$, the change in concentration is given by

$$
\frac{d C}{d t}=\frac{1}{\rho} \frac{d\left(\rho v_{s} C\right)}{d z}
$$

where $\rho$ is the air density. Tompkins [2005] shows that the solution is

$$
C_{j}^{n+1}=\frac{\frac{\rho_{j-1} v_{j-1} C_{j-1}^{n+1}}{\rho_{j} \Delta Z} \Delta t+C_{j}^{n}}{1+\frac{\rho_{j-1} v_{j}}{\rho_{j} \Delta Z} \Delta t},
$$

which is solved from top to bottom of the column.

[23] The settling velocity $v_{s}$ for a particle of radius $r$ is determined by Stokes's law,

$$
v_{s}=\frac{2 \rho_{p} g}{9 \mu} r^{2} C_{C u n n}
$$

where $\rho_{p}$ is the particle density, $g$ the acceleration of gravity, $\mu$ is the absolute viscosity of air, and $C_{C u n n}$ is the Cunningham correction to account for the viscosity dependency on air pressure and temperature.

\subsection{Hygroscopic Effects on Carbonaceous Compounds}

[24] Black carbon and organic matter aerosols are produced from the sources discussed in section 2.2.3. From those sources, the organic matter (OM) is distributed between $50 \%$ of hydrophilic and $50 \%$ of hydrophobic OM, where as for black carbon (BC), $80 \%$ is kept as hydrophobic and $20 \%$ is considered as hydrophilic BC.

[25] Once emitted, the hydrophobic component is transformed into a hydrophilic one with a time constant of 1.16 day. Therefore, aerosol mixing is only treated implicitly. This follows a similar parameterization in the LOA/LMD-Z model.

\subsection{Conversion $\mathrm{SO}_{2} / \mathrm{SO}_{4}$}

[26] Sulphur dioxide $\mathrm{SO}_{2}$ is produced at or near the surface as discussed in section 2.2.3. The transformation of $\mathrm{SO}_{2}$ into sulphate $\mathrm{SO}_{4}$ is done without any explicit chemistry. The exponential transfer from $\mathrm{SO}_{2}$ and $\mathrm{SO}_{4}$ uses a simple time constant, itself a variable with latitude (from 3 days at the equator to 8 days at the poles), as done in the 
simplified aerosol model of Huneeus [2007], itself calibrated on the results of the full LOA/LMD-Z model of Boucher et al. [2002].

\subsection{Wet Deposition}

[27] A review of GCM-type schemes to deal with wet precipitation scavenging is given by Lee and Feichter [1995] and Rasch et al. [2000]. In this study, wet deposition is computed separately for convective and large-scale precipitation using the relevant precipitation flux profiles, and following Giorgi and Chameides [1986] for the incloud scavenging.

[28] The scavenging rate $\left(\mathrm{s}^{-1}\right)$ is given by $W_{I}=\beta f D$, with $D$ the fraction of aerosol included in droplets through dissolution or impaction, $f$ the cloud volume fraction, and $\beta$ the rate of conversion of cloud water to rainwater (in $\mathrm{kg} \mathrm{kg}^{-1} \mathrm{~s}^{-1}$ ). $D$ is set to 0.7 for SS, DU, $\mathrm{SO}_{4}$ and the hydrophilic components of $\mathrm{OM}$ and $\mathrm{BC}$. The parameter $\beta$ at model level $k$ is computed from the 3D precipitation flux $P\left(\right.$ in $\mathrm{kg} \mathrm{m}^{-2} \mathrm{~s}^{-1}$ ) and the model condensed in-cloud water mixing ratio $q$ (in $\mathrm{kg} \mathrm{kg}^{-1}$ ) as

$$
\beta_{k}=\frac{P_{k}-P_{k+1}}{\rho_{\text {air }, k} \Delta z_{k} f_{k} q_{k}} .
$$

In the present model, as in work by Reddy et al. [2005], no distinction is made between rain and snow and $f$ is assumed to represent the cloud fraction over the full vertical layer.

[29] Below-cloud scavenging is computed considering the volume of space swept out by a raindrop during its fallout. The scavenging rate (in $\mathrm{s}^{-1}$ ) is given by

$$
W_{B}=\frac{3 P_{r} \alpha}{4 R_{r} \rho},
$$

where $P_{r}$ is the precipitation flux, $R_{r}$ is an average raindrop radius (set to $1 \mathrm{~mm}), \rho$ the water density $\left(\mathrm{kg} \mathrm{m}^{-3}\right)$ and $\alpha$ the efficiency with which aerosols are collected by raindrops. Values of 0.001 and 0.01 for raindrops and snowflakes were selected for $\alpha$ on the basis of measurements reported by Pruppacher and Klett [1997].

[30] The release of aerosol due to evaporation at level $k$ is equal to the amount scavenged at higher levels multiplied by the fraction of precipitation which is evaporated, with an 0.5 multiplicative factor to account for the fact that raindrops can shrink without evaporating totally. If the incoming precipitation flux totally evaporates in the layer, the aerosols are released totally as well.

\section{Results}

[31] For the results presented below, there is no assimilation of any data related to aerosol. The model, including the parameterizations for the physical aerosol processes discussed in sections 2 and 3, was run from a given initial date in a series of 12 -h forecasts starting every $12 \mathrm{~h}$ from the ECMWF operational analyses. The model aerosols are freewheeling; that is, starting from null concentrations of aerosols on the initial date, the various aerosols are spun up for about 8-12 days (the time their contents establish themselves) with aerosols produced from surface emission fluxes, and going through the physical processes (dry deposition, sedimentation, hygroscopicity, wet deposition by large-scale and convective precipitation). The aerosols at the end of a given 12-h forecast are passed as initial conditions at the start of the next 12 -h forecast. This is in essence not very different from what is done within a transport model, except for the fact that the aerosol processes are consistent with the dynamics and all other physical parameterizations.

[32] Two sets of forecasts were conducted. The first one is a series of 12-h forecasts at $T_{L} 159 \mathrm{~L} 60$ covering the period 1 December 20020000 UTC to 31 May 20052400 UTC. The second one includes experimental near-real-time 72 -h forecasts at $T_{L} 159 L 91$ started on 15 May 20070000 UTC and going on since. This last set of forecasts differs from the first one only by forecast length ( 72 versus $12 \mathrm{~h}$ ) and number of vertical levels (91 versus 60). Both sets of forecasts start from aerosol-free conditions (on 1 December 2002 or 15 May 2007, respectively) and cycle since these initial dates taking in the operational analyses for other meteorological fields every $12 \mathrm{~h}$. Although in this stage of the development of the ECMWF IFS, the prognostic aerosols developed in this project are not yet interactive with the radiation scheme, (the radiation scheme still relies on the climatological aerosols derived from Tegen et al. [1997]), the optical thicknesses for all prognostic aerosols are evaluated as diagnostic quantities that can be compared to measurements such as those taken by AERONET [Holben et al., 1998; Dubovik et al., 2002; Kinne et al., 2003, 2006], or derived from satellite measurements like those of MODIS [Remer et al., 2005].

\subsection{Observational Data Sets}

[33] Various sources of observational data have been used to verify the model aerosols. Within the GEMS project, the IFS is to provide the trajectory forecast used in the assimilation of satellite observations sensitive to the presence of aerosols. Therefore for verification of the aerosol forecast, the emphasis is put here on using such satellite and surface observations of the aerosol optical depth, as being the generally and most widely available measurement. More extensive comparisons of the model aerosols with observations in terms of their physicochemical properties will be presented in a companion paper (A. Mangold et al., Aerosol analysis and forecast in the ECMWF Integrated Forecast System: 3. Evaluation, manuscript in preparation, 2009).

[34] Satellite observations as carried out by MODIS (MODerate resolution Imaging Spectroradiometer) on the Terra and Aqua satellites provide visible optical depth at $550 \mathrm{~nm}\left(\tau_{550}\right)$ each available once a day over a wide path. MISR (Multi-angle Imaging SpectroRadiometer) on board Terra provides the aerosol optical depth at $557.5 \mathrm{~nm}$ in similar conditions, but with a coarser spatial coverage. Figure 6 displays for April 2003 the monthly mean aerosol optical depth at $550 \mathrm{~nm}$ from MODIS on Terra, MODIS on Aqua and MISR on Aqua. Figure 6 shows that $\tau_{550}$ is not retrieved at high latitudes when the solar illumination is small, nor over bright surfaces (snow over Northern Hemisphere high latitudes or the desert areas of Sahara and Australia). MISR $\tau_{557}$ displays a similar (but noisier) geographical distribution of aerosol as MODIS. Although the differences in monthly mean $\tau_{550}$ between MODIS on Aqua and Terra (not shown) are not systematic and may be 
a

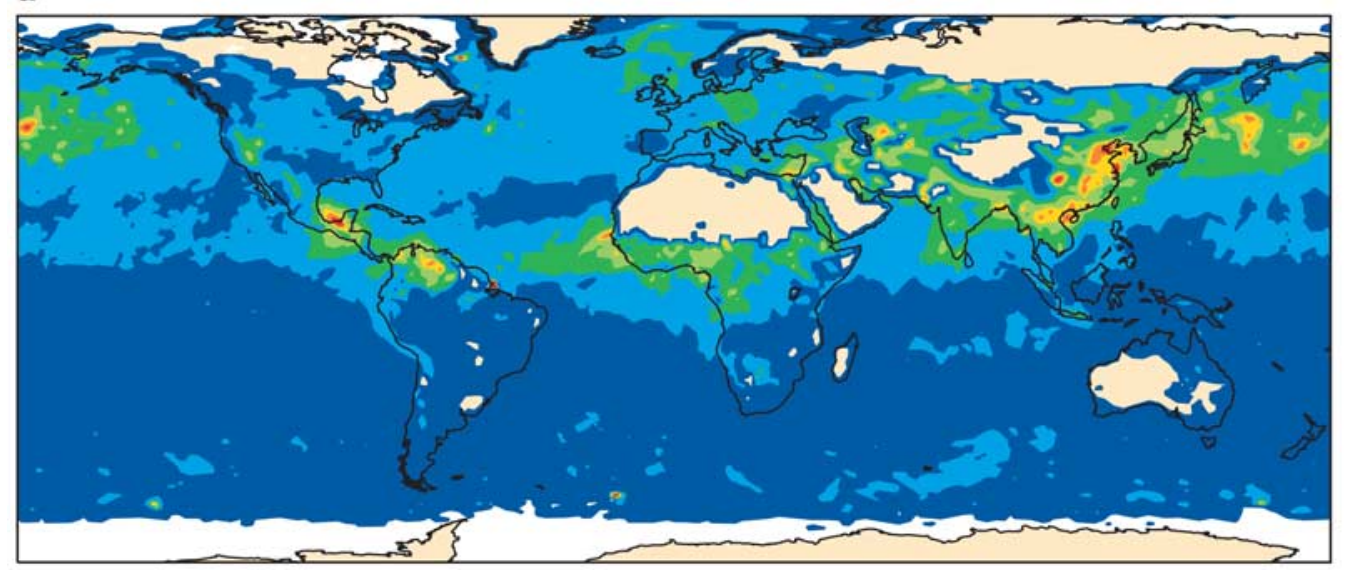

b

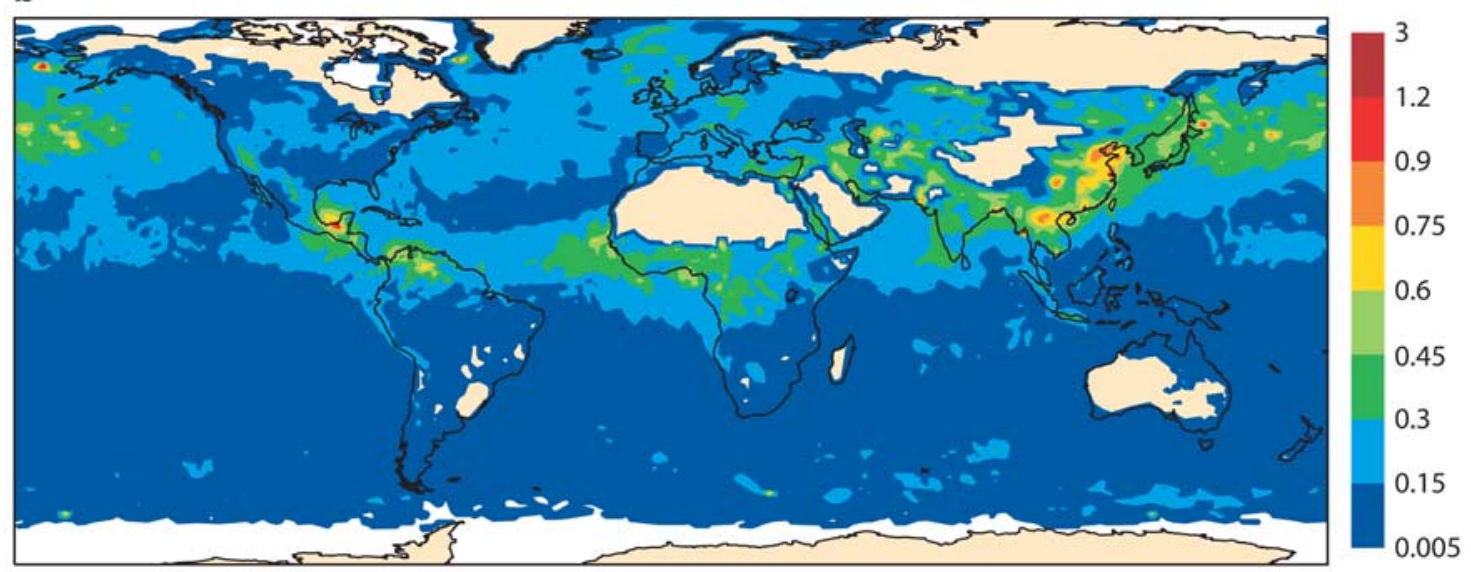

c

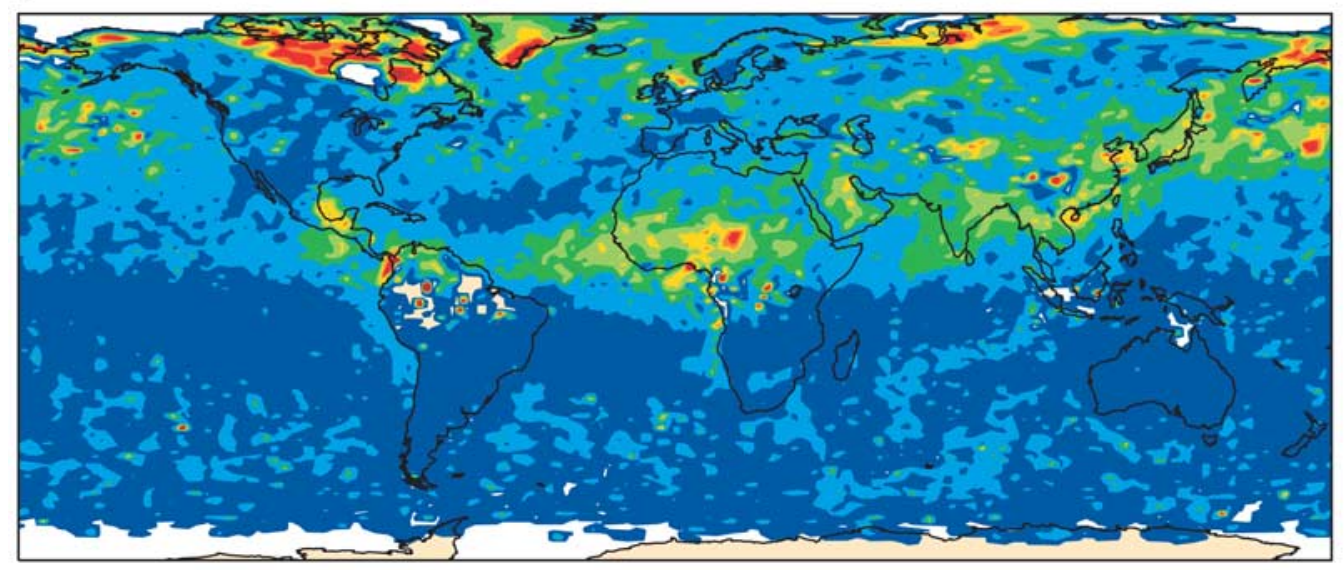

Figure 6. Aerosol optical depth around $550 \mathrm{~nm}$ retrieved from satellite measurements for the month of April 2003. Aerosol optical depth at $550 \mathrm{~nm}$ from (a) MODIS on Terra and (b) MODIS on Aqua.

(c) Optical depth at $557.7 \mathrm{~nm}$ from MISR on Terra.

due to different overpass times in some regions, there appears to be an uncertainty of \pm 0.05 on $\tau_{550}$ over a large fraction of the ocean. These differences are less extended over land.

[35] The CALIPSO lidar on the Aqua satellite provides vertical profiles of the aerosol extinction coefficient along the satellite track over a narrow track whereas the radar on board CloudSat provides a similar information on clouds [Stephens et al., 2002]. In the following, the vertical distribution of aerosols and clouds along the A-Train track within the ECMWF IFS is qualitatively compared to the cloud-aerosol mask derived from combined CloudSatCALIPSO observations (A-Train description: http:// www.nasa.gov/mission_pages/cloudsat/multimedia/atrain.html). AERONET is a federated network of ground stations measuring the solar radiation over a number of wavelengths [Holben et al., 1998]. In the absence of overlying cloudiness, these measurements are processed to 
Table 1. Satellite Observations Simulated by the ECMWF IFS With Prognostic Aerosols ${ }^{\mathrm{a}}$

\begin{tabular}{ccc}
\hline$\lambda(\mathrm{nm})$ & Observation Type & Instrument \\
\hline 340 & $\tau$ & AERONET \\
380 & $\tau$, extinction & AERONET, SAGE-3 \\
400 & $\tau$ & SEVIRI \\
443 & $\tau$ & AERONET (440), MISR (446) \\
470 & $\tau$, reflectance & MODIS (469) (land/ocean) \\
500 & $\tau$ & AERONET \\
532 & backscatter coefficient & CALIOP \\
550 & $\tau$, reflectance & MODIS (555), MISR (557) \\
645 & $\tau$, reflectance & MODIS (645) (land/ocean) \\
670 & $\tau$, extinction & MISR (672), AERONET (675), \\
& $\tau$ & SAGE-3 (676) \\
800 & $\tau$, reflectance & SEVIRI \\
858 & extinction, $\tau$ & MODIS (land/ocean) \\
865 & coefficient, $\tau$ & MISR (867), SAGE-3 (868) \\
1020 & extinction, backscatter & SAGE 3, CALIOP (1064), AERONET \\
& $\tau$, reflectance & MODIS (ocean) \\
1240 & $\tau$, reflectance & MODIS (ocean) \\
1630 & MODIS (land/ocean) \\
2130 &
\end{tabular}

${ }^{\mathrm{a}}$ AERONET, MISR, and SEVIRI (Spinning Enhanced Visible and Infrared Imager) provide optical depth $\tau$; MODIS provides reflectance and $\tau$. CALIOP (Cloud-Aerosol Lidar with Orthogonal Polarization) provides profiles of the backscattering coefficient; SAGE-3 Stratospheric Aerosol and Gas Experiment provides extinction coefficient. give the aerosol optical depth. For validating the temporal variability of the model aerosols, a number of stations (37 in April 2003) spanning the whole globe are used to compare the model optical depth to observed ones.

\subsection{Model Aerosol Optical Properties}

[36] Aerosol optical depth is diagnosed for the 17 shortwave wavelengths given in Table 1 . The different aerosol species are assumed to be externally mixed. The refractive indices were derived from work by A. A. Lacis (gacp.giss. nasa.gov/data sets/lacis/introduction.pdf) for sea salt and interpolated from work by Dubovik et al. [2002] for desert dust. Then a standard Mie scattering algorithm [Ackerman and Toon, 1981] is applied using, for sea-salt and dust aerosols, the particle size distribution as simulated by the bin scheme but also accounting for a fixed size distribution within each bin that has been calibrated against a model with more bins. Optical depth for sea salt and dust are obtained by summing the individual bin contributions (assumed to be independent in the bin representation used for the ECMWF IFS) to the optical thickness for each aerosol type.

[37] Absorption and scattering coefficients for organic and black carbon, and sulphate were adapted from those in the LOA/LMD-Z model [see Reddy et al., 2005, Table 2] and are based on work by Hess et al. [1998]. Sea-salt and

\section{a}

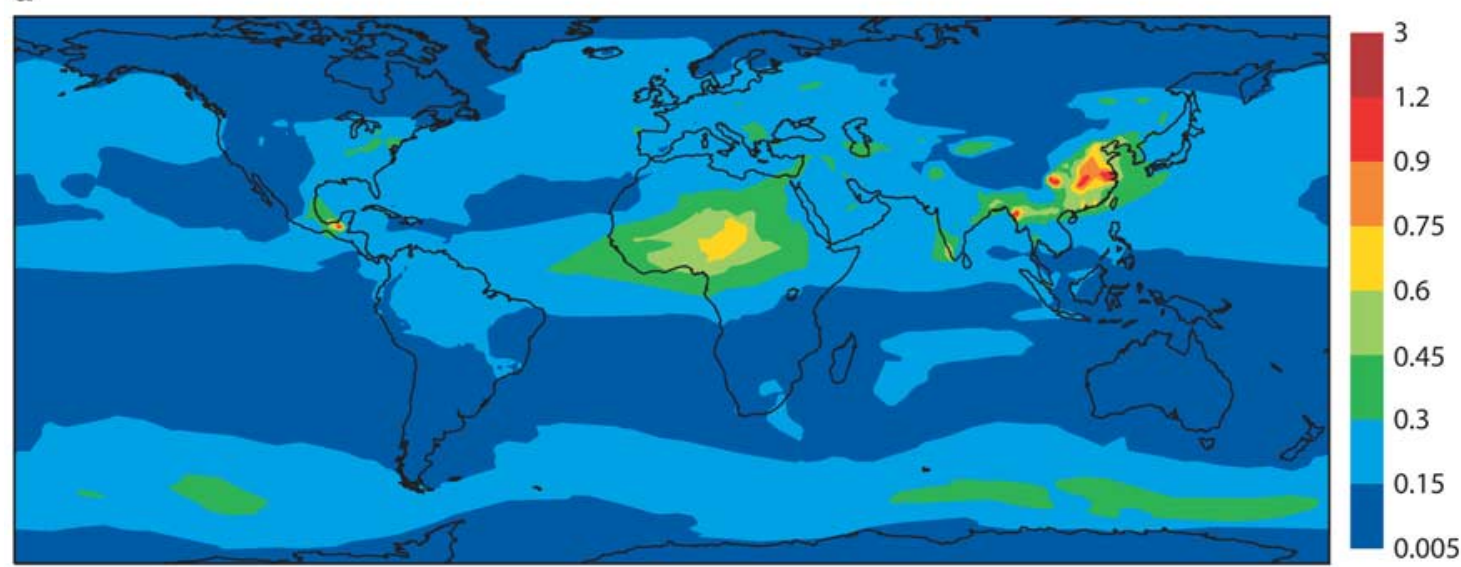

b

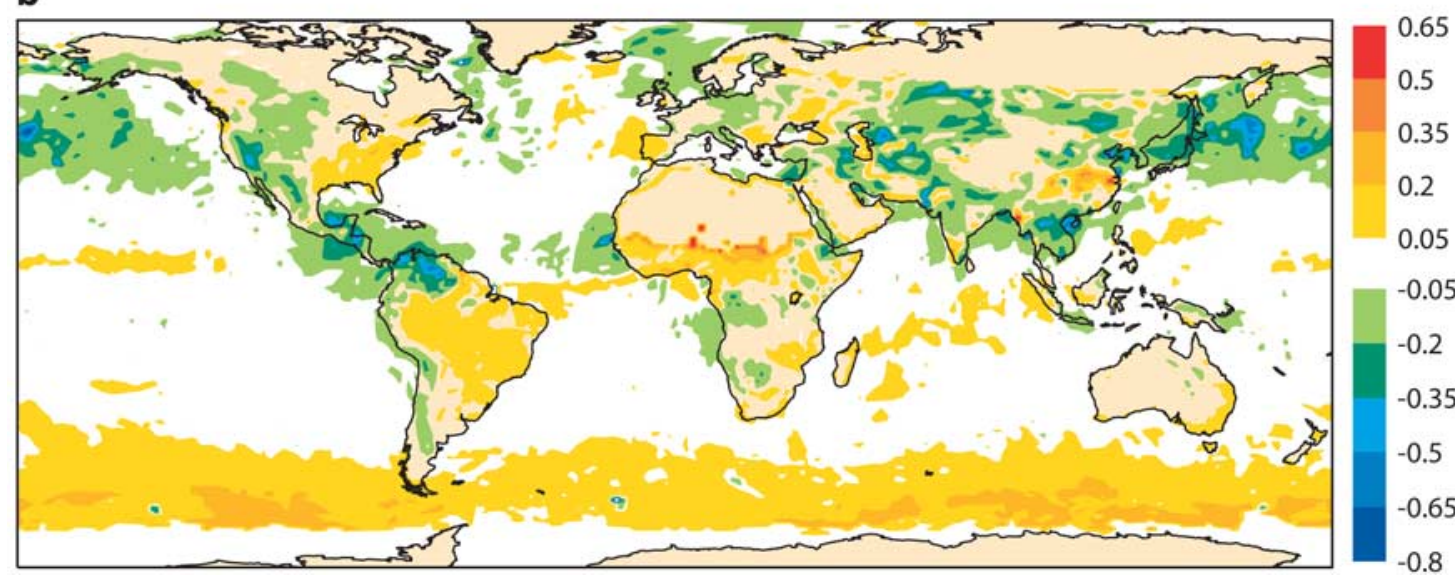

Figure 7. (a) Aerosol optical depth at $550 \mathrm{~nm}$ for April 2003 derived from the ECMWF model and (b) the difference ECMWF-MODIS. 


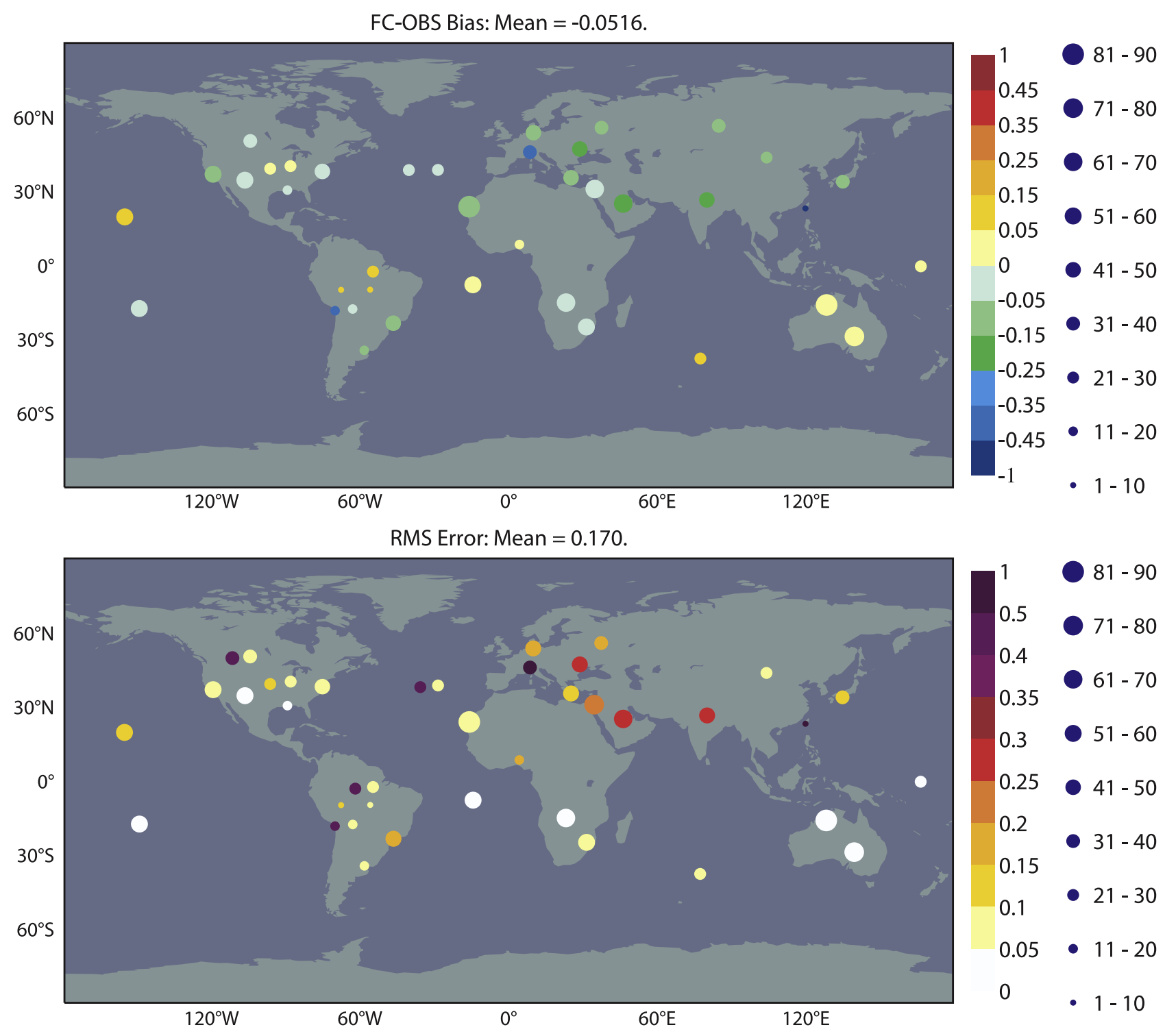

Figure 8. (top) Bias and (bottom) RMS error of the model aerosol optical depth at $550 \mathrm{~nm}$ against the AERONET observations at $500 \mathrm{~nm}$ for April 2003. Dot size varies with the number of available observations in the month.

sulphate aerosols have their optical properties depending on the local relative humidity with the relevant growth factor taken from work by Tang [1997] and Tang and Munkelwitz [1994], respectively. In the absence of reliable data for OM, the same growth factor as for $\mathrm{SO}_{4}$ is used for OM [Reddy et al., 2005].

\subsection{Monthly Mean Total Aerosol Optical Depth}

[38] Figure 7 compares the total aerosol optical depth averaged over April 2003 derived from MODIS on Terra to the one produced by the ECMWF IFS. April 2003 was selected among other months as an average month with contributions from all five aerosol types and providing a representative image of the successes and deficiencies of the prognostic aerosols in the ECMWF model. The globally averaged monthly mean optical depth for SS (0.0620), DU (0.0255) OM (0.0410), BC (0.0040) and $\mathrm{SO}_{4}(0.0278)$ respectively correspond to loading of $36.2,27.7,1.45$, 0.099 and $0.715 \mathrm{mg} / \mathrm{m}^{2}$. A number of features of the aerosol distribution are present in both data sets, namely the desert dust over Sahara, anthropogenic aerosols over central Europe, south India and eastern China, the effect of fires in Mexico. However, the comparison between the model and the MODIS observations also shows too large $\tau_{550}$ over the Southern Hemisphere storm track (likely to be linked to too large production of sea-salt aerosols), too little $\tau_{550}$ over central Africa (biomass burning), Central America and downwind of Asia over the North Pacific.

[39] Comparing the model $\tau_{550}$ to the AERONET $\tau_{500}$ on a monthly mean basis (for April 2003), Figure 8 further points out a deficit of aerosols in northern and eastern Europe, Saudi Arabia and northern India (between - 0.025 and -0.25) and a large one for the Arica station (northern Chile) where aerosols linked to copper smelters are not well represented in the emission data sets. Although from theoretical considerations, $\tau_{550}$ can be expected to be slightly smaller than $\tau_{500}$, the difference in wavelength cannot 

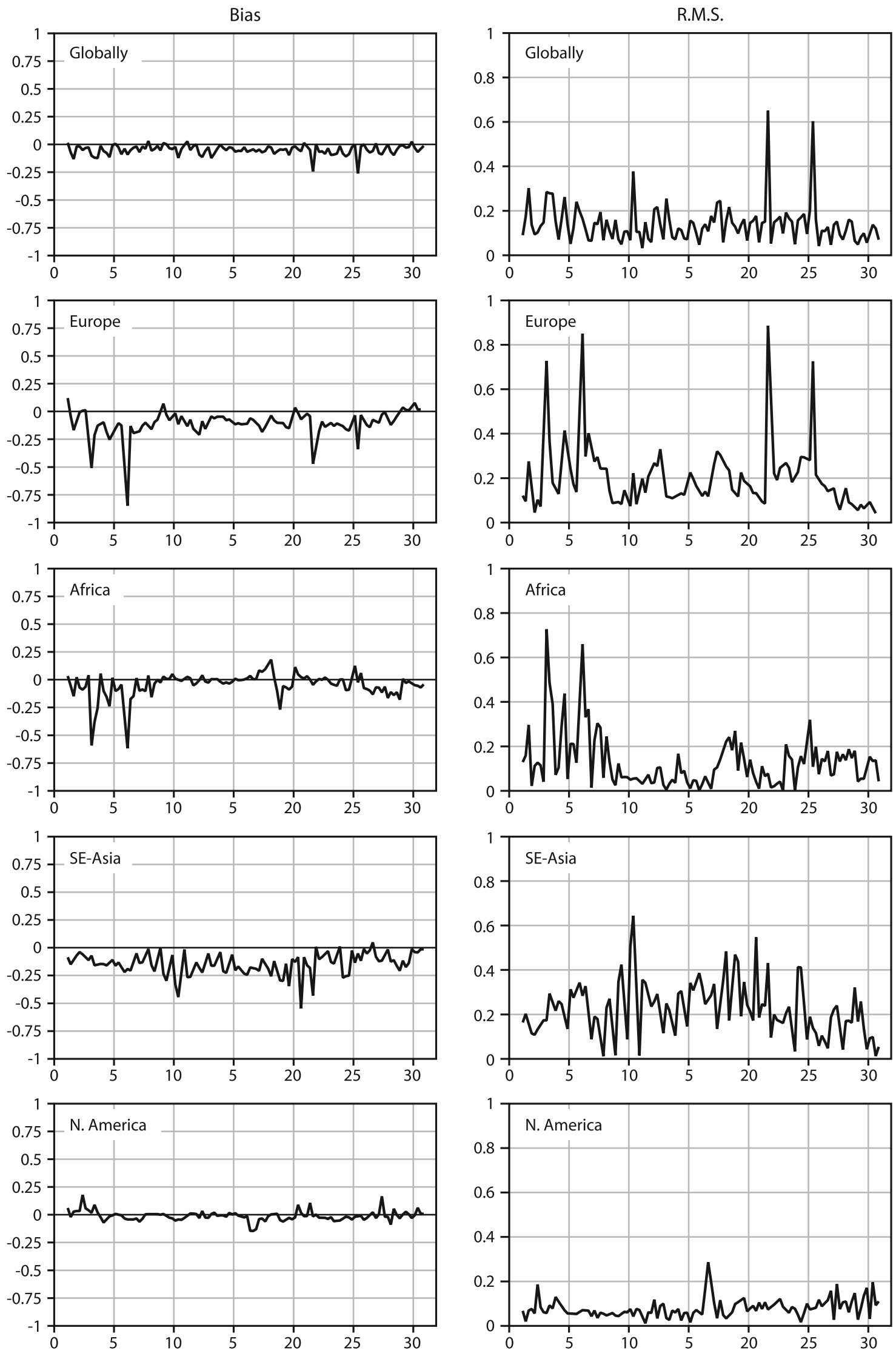

Figure 9. Statistics of comparisons of the model $\tau_{550}$ with $\tau_{500}$ observed at AERONET stations for the 30 days of April 2003, over the globe, Europe, Africa, Southeast Asia, and North America. (left) Bias and (right) RMS error (nondimensional). 

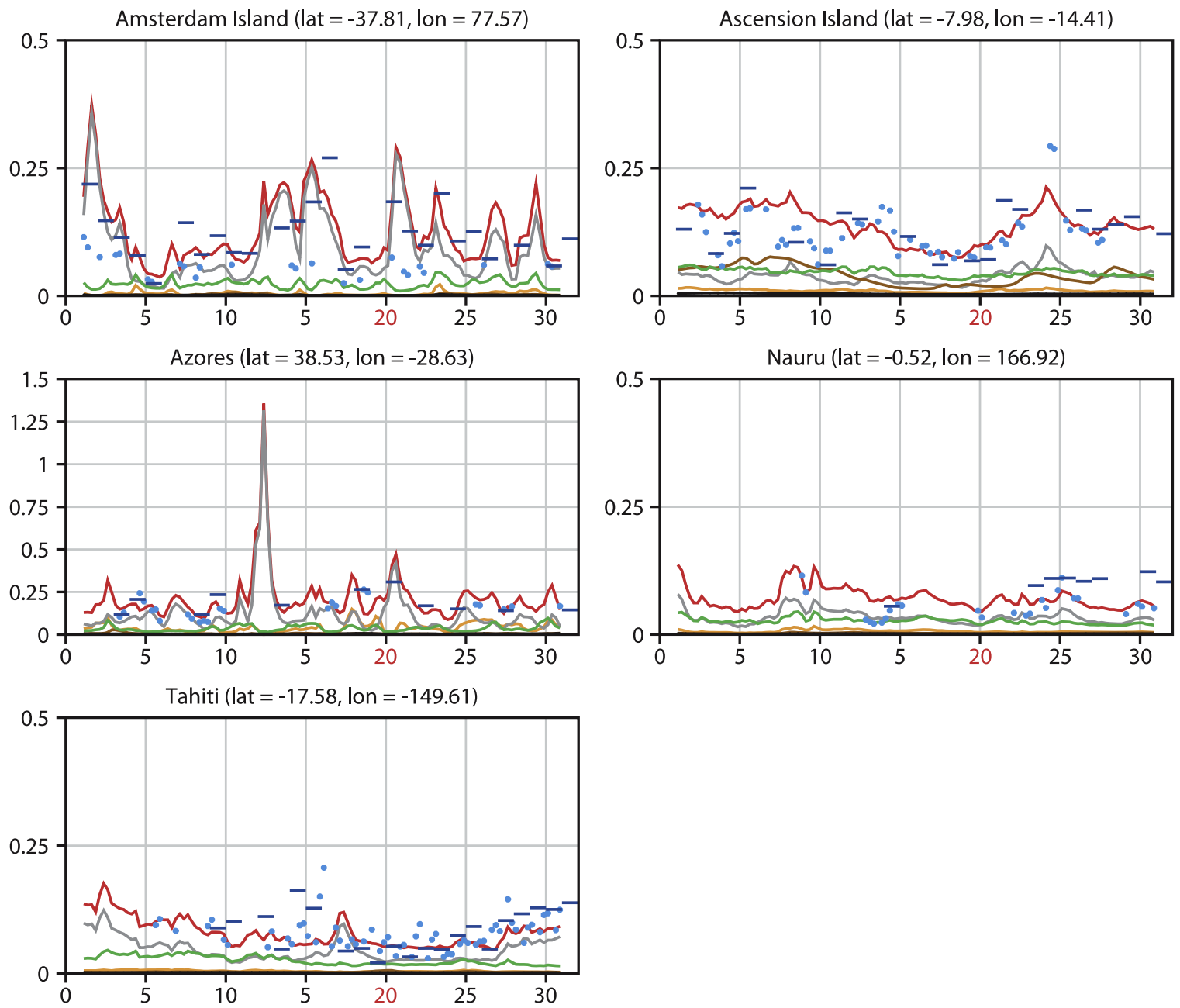

Figure 10. Time series of the optical depth at $500 \mathrm{~nm} / 550 \mathrm{~nm}$ over five stations where sea-salt aerosols are dominant. AERONET observations at $500 \mathrm{~nm}$ are given by blue-grey circles, and MODIS $\tau_{550}$ is given by blue segments. The total model optical depth at $550 \mathrm{~nm}$ is in red. Other lines are for the various aerosol components: sea-salt (grey), dust (brown), organic carbon (green), black carbon (black), and sulphate (orange).

explain the differences between model and AERONET observations.

\subsection{Time Variability of the Aerosol Optical Depth}

[40] Figure 9 presents the time evolution of the bias and RMS error of the model total aerosol optical depth relative to a set of 37 AERONET stations over the globe, in Europe, Africa, Southeast Asia and North America. Bias and RMS error are computed over the hourly time slots when observations are present. The biases are generally negative (by 0.1 to 0.25 over Southeast Asia), showing an underestimation of $\tau_{550}$ in the model. The RMS error is on average below 0.2 with much higher peaks corresponding to aerosol events, not seen by the model, usually because of sources not displaying increased emissions. For a number of individual stations where either sea-salt, desert dust, or anthropogenic aerosols dominate the total aerosol optical depth, Figures 10 to 12 display the evolution of the bias and RMS error in $\tau_{550}$ relative to AERONET measurements and the corresponding MODIS optical depth, when available.

[41] Figure 10 considers stations where sea-salt aerosols are likely to be dominant (Amsterdam Island $37.81^{\circ} \mathrm{S}-$ $77.57^{\circ} \mathrm{E}$, Ascension Island $7.98^{\circ} \mathrm{S}-14.41^{\circ} \mathrm{W}$, Azores $38.53^{\circ} \mathrm{N}-28.63^{\circ} \mathrm{W}$, Nauru $0.52^{\circ} \mathrm{S}-166.92^{\circ} \mathrm{E}$, Tahiti $\left.17.58^{\circ} \mathrm{S}-149.61^{\circ} \mathrm{W}\right)$. Overall the agreement between model and observations is good with a proper representation of the temporal variability. Figure 11 presents similar comparisons for stations where dust aerosols are prevalent (Dahkla $23.72^{\circ} \mathrm{N}-15.95^{\circ} \mathrm{W}$, Dalanzadgad $43.58^{\circ} \mathrm{N}-104.42^{\circ} \mathrm{E}$, Forth Crete $35.53^{\circ} \mathrm{N}-25.28^{\circ} \mathrm{E}$, Sede Boker $30.86^{\circ} \mathrm{N}-$ $34.78^{\circ} \mathrm{E}$, Solar Village $24.91^{\circ} \mathrm{N}-46.40^{\circ} \mathrm{E}$ ). For these stations for which sudden increases in aerosol optical depth are linked to dust plumes, the agreement is also good, with a correct representation of the background aerosol optical depth and of the timing of the sudden increases. However, as can be seen particularly for Sede Boker and Solar Village, the amplitude of these events is generally underestimated by the model. Figure 12 considers comparisons over stations where anthropogenic aerosols dominate the total aerosol optical depth (Bondville $40.05^{\circ} \mathrm{N}-88.37^{\circ} \mathrm{W}$, Hamburg $53.57^{\circ} \mathrm{N}-9.97^{\circ} \mathrm{E}$, Moldova $47.00^{\circ} \mathrm{N}-28.82^{\circ} \mathrm{E}$, Sao Paulo $23.56^{\circ} \mathrm{S}-46.73^{\circ} \mathrm{W}$, Shirahama $33.69^{\circ} \mathrm{N}-$ $135.36^{\circ} \mathrm{E}$, Wallops $37.94^{\circ} \mathrm{N}-75.47^{\circ} \mathrm{W}$ ). For these stations, even when the average optical depth over the month is 

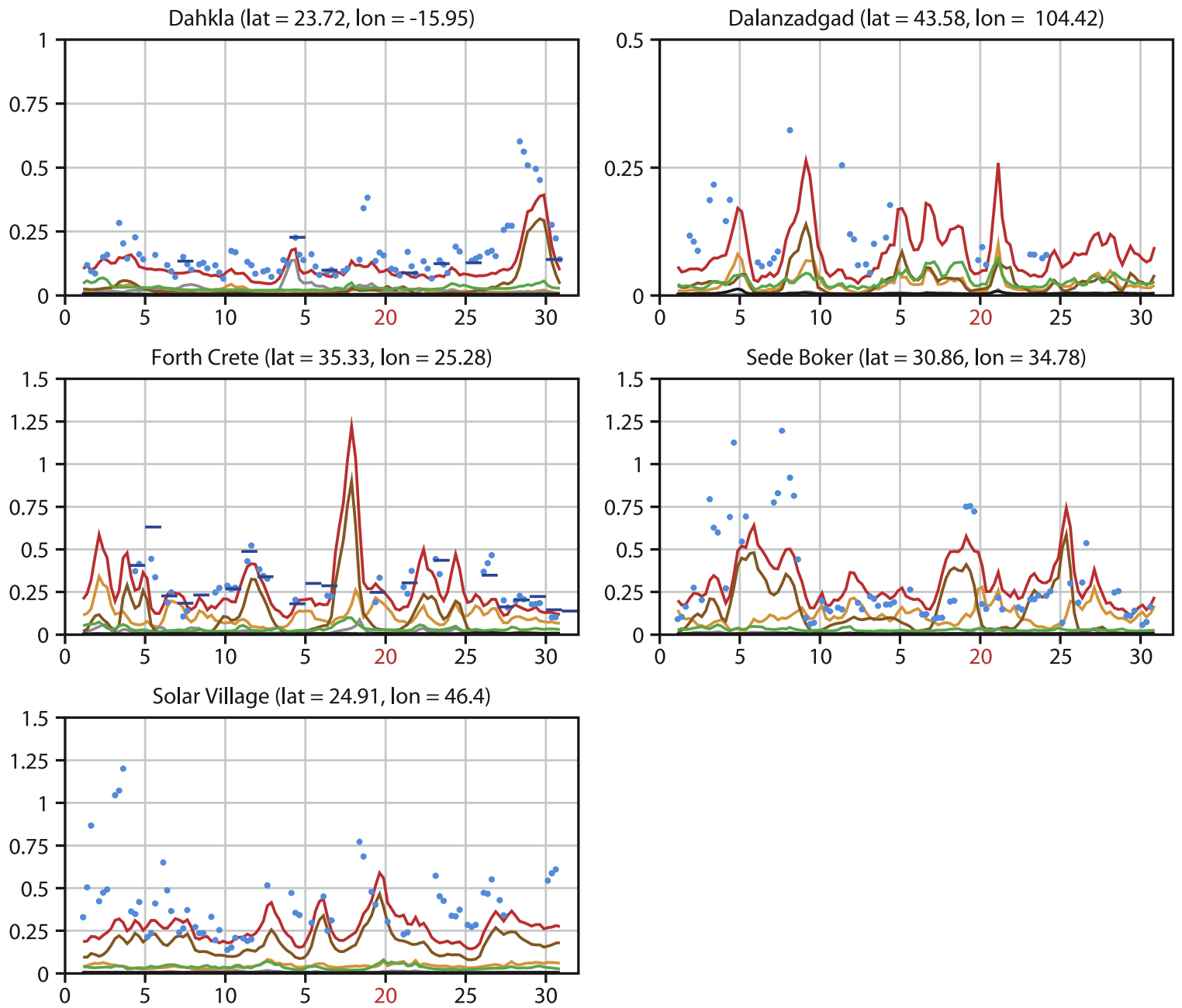

Figure 11. As in Figure 10 but for five stations where dust aerosols are prevalent.

reasonable, the model temporal variability only reflects the quality of the dynamics of the ECMWF IFS. If the sources of aerosols in upwind regions are reasonably represented (Bondville, Wallops), a proper timing of the fluctuations in $\tau_{550}$ is seen. If the sources are not well included (either in timing or intensity of the emissions), either the fluctuations are out of phase (Sao Paulo, Shirahama) or the aerosol optical depth is underestimated (Hamburg, Moldova).

\subsection{Vertical and Horizontal Distribution of the Aerosol Layers}

[42] Plumes of aerosols of desert origin are not uncommon over Europe. Three such plumes were observed coming out of Africa on 4, 15 and 30 April 2003. Figure 13 compares qualitatively the MODIS visible imagery and $\tau_{550}^{D U}$ for one such event on 15 April 2003. In all three cases, the model displays a plume of desert aerosols in the area of concern showing that, given a source of dust over Africa, the dynamics of the model is successful at distributing spatially the aerosols with the proper timing. However, the representation of the actual intensity of these events is much more difficult to capture, with, for example, too large an intensity on 4 April (not shown) and too small on 15 (Figure 13) and 30 April (not shown).
[43] Figure 14 illustrates the potential of the future aerosol forecasts, in terms of instantaneous vertical and horizontal distributions of aerosols. For an ascending orbit over Africa (Figure 14a), a classification of cloud and aerosol produced by the CALIPSO Science Team (Figure 14c) is compared with the corresponding model cloud and aerosol (Figure 14d). Even for this relatively low horizontal resolution $\left(T_{L} 159\right)$, the ECMWF model generally produces the cloud and aerosol in the proper location both horizontally and vertically. Over the same orbit, the total aerosol optical depth at $550 \mathrm{~nm}$ produced by the model (Figure 14b) is compared to the equivalent optical depth retrieved from MODIS observations over ocean and dark land surfaces in absence of extended cloud cover. For desert dust, the agreement is usually good reflecting the high quality of the initial conditions and of the atmospheric motions in the subsequent $72-\mathrm{h}$ forecast. Over central Africa, the sources of sulphate, organic and black carbon aerosols linked to biomass burning are well represented in the inventories, and the agreement on the optical depth of the plume moving toward the South Atlantic is also good.

\subsection{Multispectral Optical Depth Diagnostics}

[44] The optical thickness in the seven MODIS shortwave channels is available in both sets of simulations discussed 

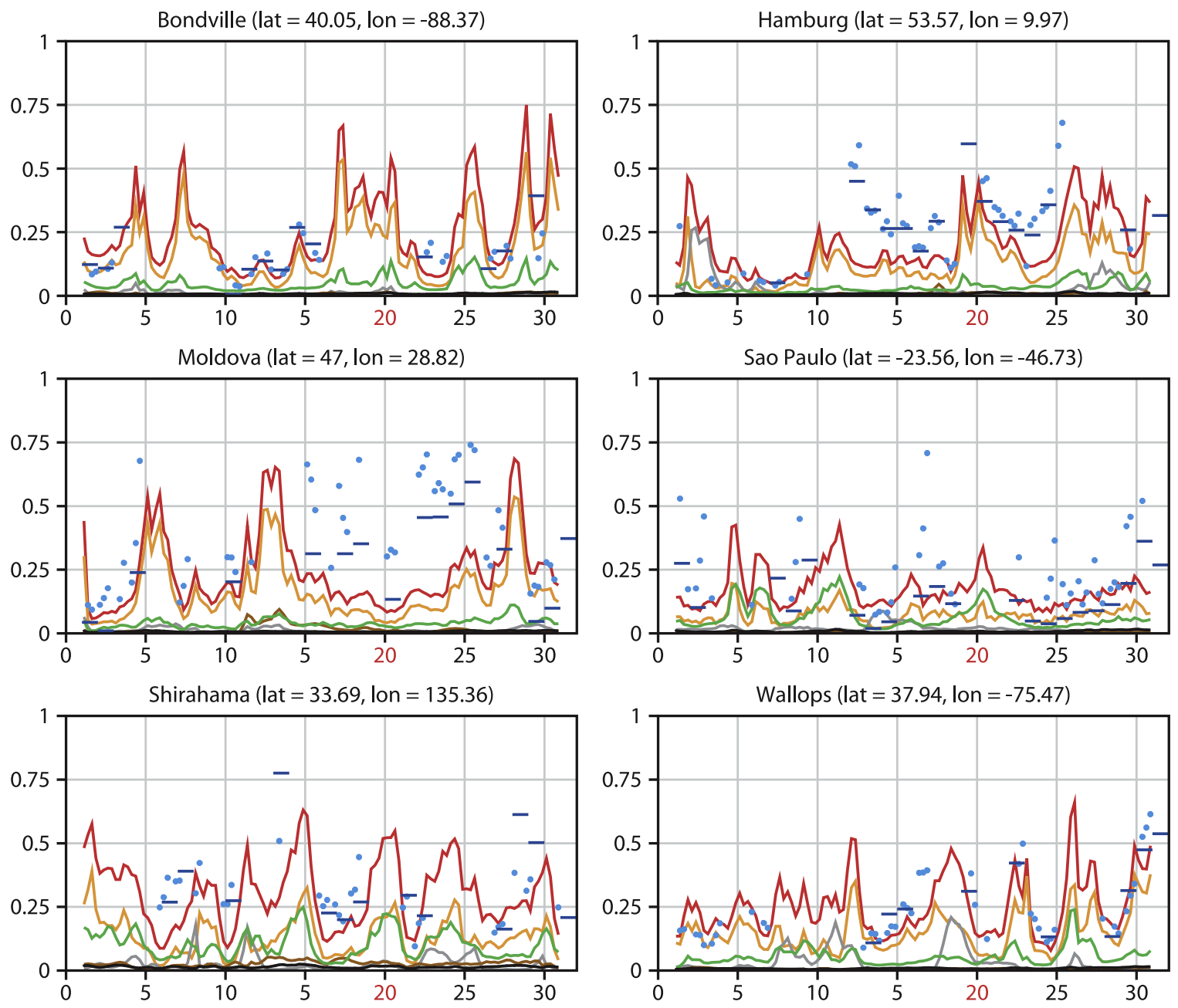

Figure 12. As in Figure 10, but for six stations where aerosols of anthropogenic origin are prevalent.

above. As expected, different aerosol types, dominant in different locations, have a distinct spectral signature. The sea-salt aerosols (dominant in the Southern Hemisphere storm track) display a rather flat spectral signature with almost no variation in optical thickness between 469 and $2130 \mathrm{~nm}$. Desert dust aerosols (Sahara) show a steady decrease in optical thickness with increasing wavelength. Black carbon aerosols (central Africa) display a rapid decrease from 469 to $865 \mathrm{~nm}$, then keep a roughly constant value of optical thickness at longer wavelengths. These spectral characteristics, related to the physical composition of the aerosols, will obviously help in the validation of the prognostic aerosols against multispectral surface and satellite measurements. This will also form the basis of the variational assimilation of aerosols using radiances, which will be tested, in the future, in the analysis part of GEMS-Aerosol.

\section{Conclusions and Perspectives}

[45] This paper has presented the representation of tropospheric aerosols, now included in an experimental version of the ECMWF forecast system. It has detailed the various parameterizations introduced for dealing with the sources and sinks of the sea-salt, dust, organic matter and black carbon and sulphate aerosols. The quality or otherwise of the resulting aerosols has been documented through comparisons with monthly mean optical depths from MODIS and MISR (for mean horizontal distributions), through comparisons with time series of optical depths at a number of AERONET sites (for temporal variability), and through some comparisons with the CALIPSO cloudaerosol masks for vertical distributions. This report has concentrated on the forward model providing the trajectory calculations used for the 4D-Var assimilation of aerosolrelated observations discussed by Benedetti et al. (submitted manuscript, 2009).

[46] The experimental aerosol model discussed here is likely to undergo further developments. Such potential improvements will be reported elsewhere. However, the results presented here show that this version of the IFS including a relatively simple prognostic representation of the main aerosols produces reasonable stand-alone forecasts even without a previous aerosol analysis. Therefore, it already offers a good starting point for the analysis of aerosol-related observations into the 4D-Var assimilation system. One of the priorities will be to decrease further the bias in the forward model. Again, it has to be stressed that the forward model discussed here might not include all the sophistication encountered in some climate-orientated 

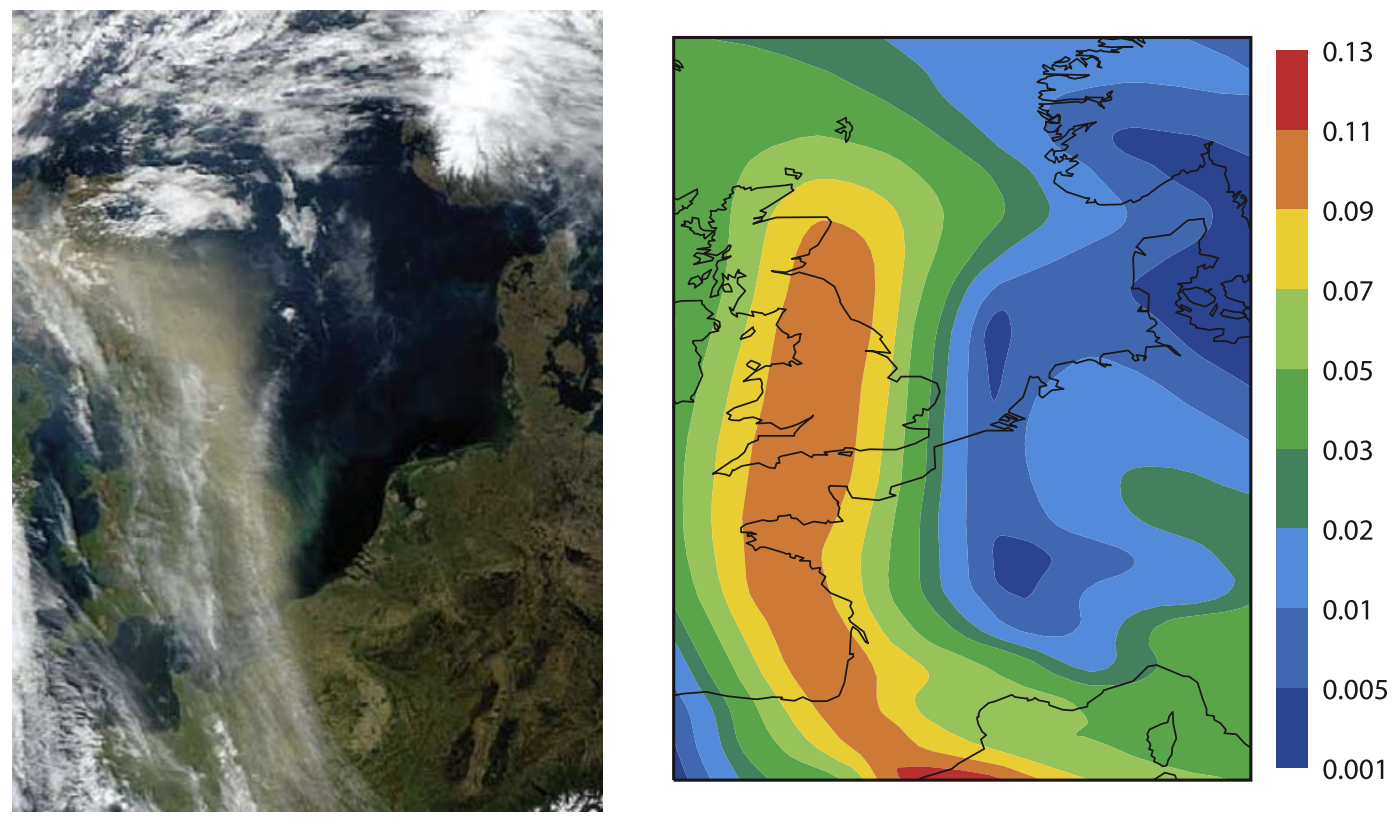

Figure 13. (left) MODIS imagery for a desert dust plume of aerosols on 15 April 2003 (courtesy, Louis Gonzalez, Laboratoire d'Optique Atmosphérique de Lille, France). (right) Corresponding optical depth at $550 \mathrm{~nm}$ for desert dust aerosols produced by the ECMWF forecasts started every $12 \mathrm{~h}$ from operational analyses, and including prognostic aerosols, started from aerosol-free conditions on 1 December 2002 and cycling since that initial date.

a Satellite track

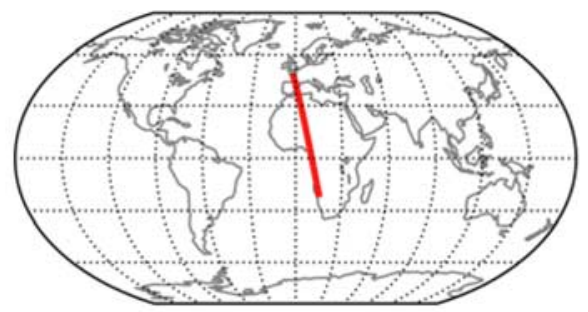

b Aerosol optical depth at $550 \mathrm{~nm}$ MODIS

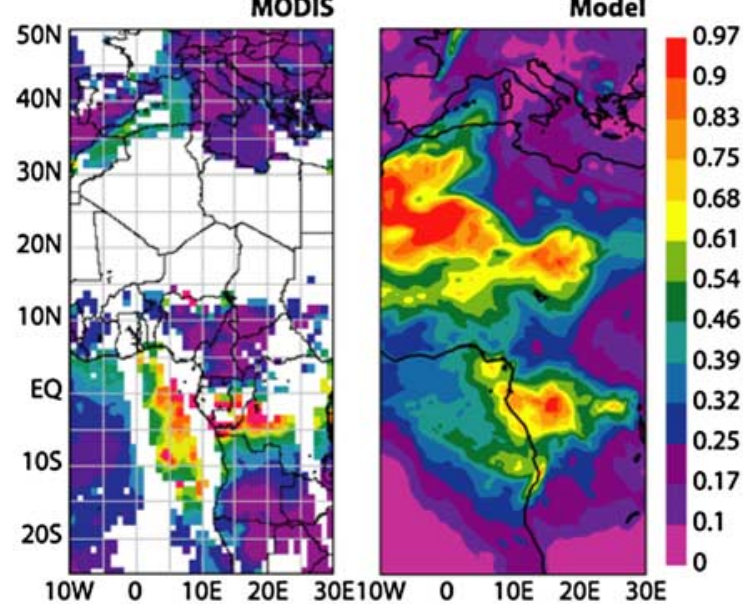

\section{c Cloud / aerosol classification from CALIPSO}
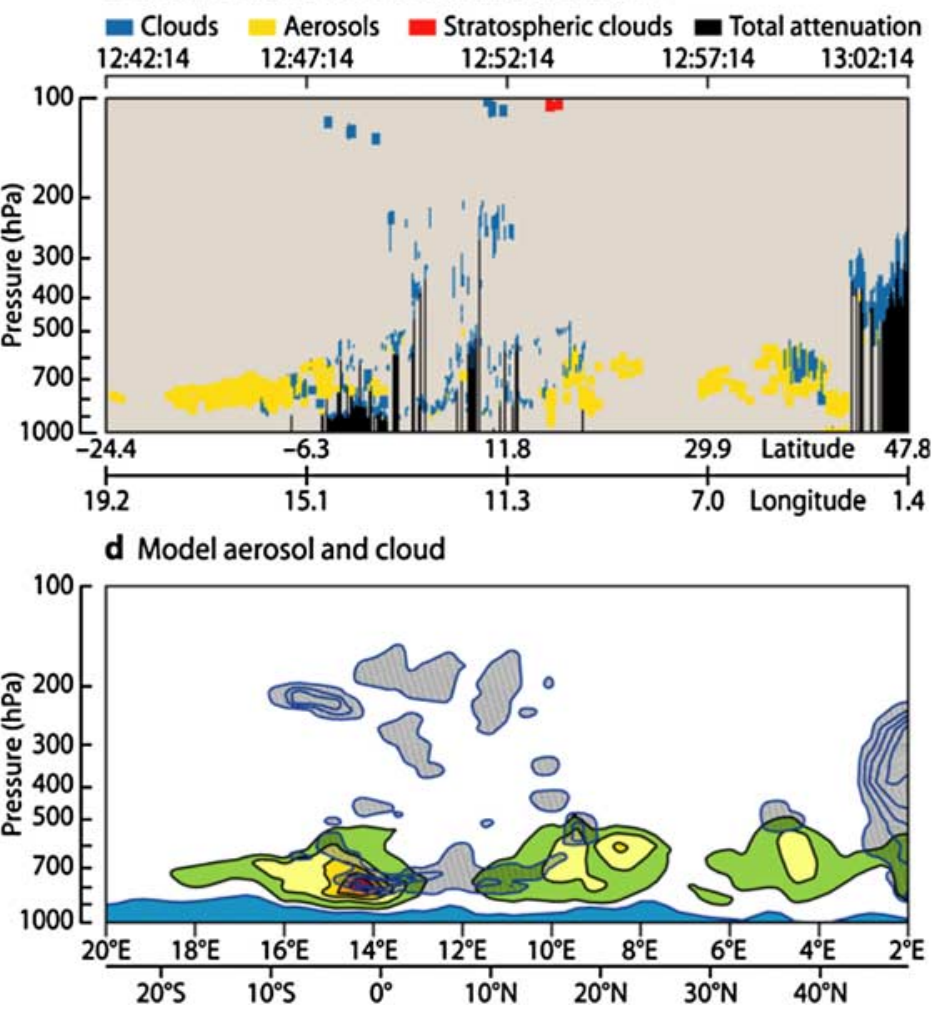

Figure 14. (a) Orbit of the A-Train of satellites on 16 July 2007 between 1242 and 1302 UTC. (b) The aerosol optical depth at $550 \mathrm{~nm}$ (left) derived from MODIS-Aqua observations and (right) produced by the ECMWF forecast model. (c) The cloud/aerosol classification derived from CALIPSO measurements along the orbit shown in Figure 14a. (d) The cross section along the same orbit as used for Figure 14c showing the aerosol (yellow/green) and cloud (grey) quantities produced by the ECMWF forecast model. The MODIS and CALIPSO data were downloaded from the NASA Giovanni server. 
general circulation models including prognostic aerosols. In the configuration described here, the forecast takes about twice as long as a forecast run without aerosols, with the increased cost stemming from the larger number of 3-D prognostic variables (from 5 to 17 ) and a more involving package of physical parameterizations (see Figure 1). The model presented here offers a good trade-off between the computer efficiency and the quality of the resulting aerosol fields, both required for use as forward model in an analysis scheme.

[47] Since 15 May 2007, this experimental version of the forecast model including aerosols has been running at $T_{L} 159$ L91 producing a near-real-time aerosol forecast available from the ECMWF web site (GEMS-AER experimental near-real-time aerosol forecast: http://gems.ecmwf. int/d/products/aer/realtime/).

[48] The quality of the results of the forward model depends not only on the dynamics of the model and the adequacy of the aerosol physical parameterizations, but also on the representativeness of the sources. With the exact sources of aerosols (in particular, those of anthropogenic origin) not available in real time, the aerosol analysis, through the assimilation of aerosol-related observations, will provide initial conditions more representative of the true aerosol distribution in the atmosphere. The development of a successful aerosol analysis is therefore fundamental to the quality of the subsequent aerosol forecast. Here the forecast model including prognostic aerosols was shown to provide a reasonable basis for this analysis.

[49] How successful the model is at reproducing the temporal variability of the aerosol load depends mainly on the quality of the model dynamics. In that respect, the results indicate that the model advection is very dependable in describing the maxima and minima of the aerosol optical depth over most stations. Whether the overall amplitude of the model optical depth is consistent with what is observed depends for a large part on which aerosol type is dominant and when anthropogenic aerosols dominate the optical depth, on the quality of the information on the sources of aerosols.

[50] The ECMWF model fields were compared to the equivalent fields compiled within the framework of AEROCOM (http://nansen.ipsl.jussieu.fr/AEROCOM, and GEMS-AER comparisons with AERONET: http:/gems. ecmwf.int/d/products/aer/verif/exlz-ezub/), the Aerosol Comparisons between Observations and Models project. As discussed by Textor et al. [2006], even for the natural sea-salt and desert dust aerosols, there is a wide diversity, not only in emission, but also in the partitioning between wet and dry deposition, and between gravitational settling and turbulent deposition. This results in a reasonable agreement between models as far as total optical thickness is concerned, but different distributions between aerosol types, as well as different vertical distributions of aerosols. At the end of this stage, the main message is that the ECMWF model can handle prognostic aerosols reasonably well, and be within the "accepted" diversity of the AEROCOM results.

[51] Acknowledgments. This report is dedicated to the memory of Tony Hollingsworth, whose vision and energy made the GEMS project possible. GEMS is funded by the European Commission under the EU
Sixth Research Framework Programme, contract SIP4-CT-2004-516099. Comments by Y. Balkanski (LSCE), and discussions with G. Balsamo (ECMWF) helped define the various representations used in time for the emission of dust. At ECMWF, R. Engelen is thanked for help in merging the prognostic aerosol model into successive versions of the operational IFS, and A. Bowen and R. Hine are thanked for improving the figures to publication standards. Observational data for the individual stations in Figures 10,11 , and 12 were obtained from the AERONET web site. B. Holben and his collaborators are thanked for maintaining the AERONET sites used in this study. L. Gonzalez (LOA, Universite de Lille) provided the MODIS imagery in Figure 13. The MODIS, MISR, and CALIPSO data were downloaded from the NASA Giovanni server.

\section{References}

Ackerman, T. P., and O. B. Toon (1981), Absorption of visible radiation in atmosphere containing mixtures of absorbing and non-absorbing particles, Appl. Opt., 20, 3661-3667.

Boucher, O., M. Pham, and C. Venkataraman (2002), Simulation of the atmospheric sulfur cycle in the LMD GCM: Model description, model evaluation, and global and European budgets, Note 23, 26 pp., Inst. Pierre-Simon Laplace, Paris, France. (Available at http://www.ipsl.jussieu. $\mathrm{fr} /$ poles/Modelisation/NotesSciences.htm)

Dentener, F., et al. (2006), Emissions of primary aerosol and precursor gases in the years 2000 and 1750 prescribed data-sets for AeroCom, Atmos. Chem. Phys., 6, 4321-4344. (Available at http://www.atmoschem-phys.net/6/4321/2006/acp-6-4321-2006.pdf)

Dubovik, O., B. Holben, T. F. Eck, A. Smirnov, Y. J. Kaufman, M. D. King, D. Tanré, and I. Slutsker (2002), Variability of absorption and optical properties of key aerosol types observed in worldwide locations, J. Atmos. Sci., 59, 590-608.

Engelstaedter, S., and R. Washington (2007), Temporal controls on global dust emissions: The role of surface gustiness, Geophys. Res. Lett., 34, L15805, doi:10.1029/2007GL029971.

Fitzgerald, J. W. (1975), Approximation formula for the equilibrium size of an aerosol particle as a function of its dry size and composition, and the ambient relative humidity, J. Appl. Meteorol., 14, 1044-1049.

Gillette, D. A., J. Adams, A. Endo, and D. Smith (1980), Threshold velocities for input of soil particles in the air by desert soils, J. Geophys. Res., 85, 5621-5630.

Ginoux, P., M. Chin, I. Tegen, J. Prospero, B. N. Holben, O. Dubovik, and S.-J. Lin (2001), Sources and distributions of dust aerosols simulated with the GOCART model, J. Geophys. Res., 106, 20,255-20,274.

Giorgi, F., and W. L. Chameides (1986), Rainout lifetimes of highly soluble aerosols and gases as inferred from simulations with a general circulation model, J. Geophys. Res., 91, 14,367-14,376.

Grini, A., G. Myhre, J. K. Sundet, and I. S. A. Isaksen (2002), Modeling the annual cycle of sea salt in the global 3D model Oslo CTM2: Concentrations, fluxes and radiative impact, J. Clim., 15, 1717-1730.

Guelle, W., M. Schulz, Y. Balkanski, and F. Dentener (2001), Influence of the source formulation on modeling the atmospheric global distribution of the sea salt aerosol, J. Geophys. Res., 106, 27,509-27,524.

Hess, M., P. Koepke, and I. Schult (1998), Optical properties of aerosols and clouds: The software package OPAC, Bull. Am. Meteorol. Soc., 79 , $831-844$.

Holben, B. N., et al. (1998), An emerging ground-based aerosol climatology: Aerosol optical depth from AERONET, J. Geophys. Res., 103, $12,067-12,097$.

Hollingsworth, A., et al. (2008), The Global Earth-system Monitoring using Satellite and in-situ data (GEMS) project: Towards a monitoring and forecasting system for atmospheric composition, Bull. Am. Meteorol. Soc., 89, 1147-1164, doi:10.1175/2008BAMS2355.1.

Huneeus, N (2007), Assimilation variationnelle d'observations satellitaires dans un modéle atmosphérique d'aérosols, thèse, 225 pp., Univ. des Sci. et Technol. de Lille, Lille, France.

Kinne, S., et al. (2003), Monthly averages of aerosol properties: A global comparison among models, satellite data, and AERONET ground data, J. Geophys. Res., 108(D20), 4634, doi:10.1029/2001JD001253.

Kinne, S., et al. (2006), An AeroCom initial assessment: Optical properties in aerosol component modules of global models, Atmos. Chem. Phys., 6, $1815-1834$

Klinker, E., F. Rabier, G. Kelly, and J.-F. Mahfouf (2000), The ECMWF operational implementation of four-dimensional variational assimilation. Part III: Experimental results and diagnostics with operational configuration, Q. J. R. Meteorol. Soc., 126A, 1191-1215.

Lee, H. N., and H. Feichter (1995), An intercomparison of wet precipitation scavenging schemes and the emission rates of ${ }^{222} \mathrm{Rn}$ for the simulation of global transport and deposition of ${ }^{210} \mathrm{~Pb}, J$. Geophys. Res., 100, 23,253-23,270.

Marticorena, B., and G. Bergametti (1995), Modeling the atmospheric dust cycle: 1 . Design of a soil-derived dust emission scheme, J. Geophys. Res., $100,16,415-16,430$. 
Monahan, E. C., D. E. Spiel, and K. L. Davidson (1986), A model of marine aerosol generation via whitecaps and wave disruption, in Oceanic Whitecaps, edited by E. C. Monahan and G. MacNiocaill, pp. 167-174, D. Reidel, Norwell, Mass.

Pruppacher, H. R., and J. D. Klett (1997), Microphysics of Clouds and Precipitation, 2nd rev. and enlarged ed., 954 pp., Kluwer Acad., Boston, Mass.

Rabier, F., H. Jarvinen, E. Klinker, J.-F. Mahfouf, and A. Simmons (2000), The ECMWF operational implementation of four dimensional variational assimilation: Part I: Experimental results with simplified physics, $Q$. J. R. Meteorol. Soc., 126A, 1143-1170.

Rasch, P. J., et al. (2000), An assessment of scavenging and deposition processes in global models: Results from the WCRP Cambridge workshop of 1995, Tellus, Ser. B, 52, 1025-1056.

Reddy, M. S., O. Boucher, N. Bellouin, M. Schulz, Y. Balkanski, J.-L. Dufresne, and M. Pham (2005), Estimates of global multicomponent aerosol optical depth and direct radiative perturbation in the Laboratoire de Météorologie Dynamique general circulation model, J. Geophys. Res., 110, D10S16, doi:10.1029/2004JD004757.

Remer, L. A., et al. (2005), The MODIS aerosol algorithm, products and validation, J. Atmos. Sci., 62, 947-973.

Rodwell, M. (2005), The local and global impact of the recent change in model aerosol climatology, ECMWF Newsl., 105, 17-23.

Schulz, M., G. de Leeuw, and Y. Balkanski (2004), Sea-salt aerosol source functions and emissions, in Emission of Atmospheric Trace Compounds, edited by C. Granier, P. Artaxo, and C. E. Reeves, pp. 333-354, Kluwer Acad., Norwell, Mass.

Schulz, M., et al. (2006), Radiative forcing by aerosols as derived from the AeroCom present-day and pre-industrial simulations, Atmos. Chem. Phys., 6, 5225-5246.

Smith, M. H., and N. M. Harrison (1998), The sea spray generation function, J. Aerosol Sci., 29, Suppl. 1, S189-S190.

Smith, M. H., P. M. Park, and I. E. Consterdine (1993), Marine aerosol concentrations and estimated fluxes over the sea, Q. J. R. Meteorol. Soc., $119,809-824$.

Stephens, G. L., et al. (2002), The CloudSat mission and the A-Train, Bull. Am. Meteorol. Soc., 83, 1771-1790.

Tang, I. N. (1997), Thermodynamic and optical properties of mixed-salt aerosols of atmospheric importance, J. Geophys. Res., 102, 1883-1894, doi:10.1029/96JD03085.

Tang, I. N., and H. R. Munkelwitz (1994), Water activities, densities and refractive indices of aqueous sulfates and sodium nitrate droplets of atmospheric importance, J. Geophys. Res., 99, 18,801-18,808.

Tanré, D., J.-F. Geleyn, and J. M. Slingo (1984), First results of the introduction of an advanced aerosol-radiation interaction in the ECMWF low resolution global model, in Aerosols and Their Climatic Effects, edited by H. E. Gerber, pp. 133-177, A. Deepak, Hampton, Va.

Tegen, I., and I. Fung (1994), Modeling of mineral dust in the atmosphere: Sources, transport and optical thickness, J. Geophys. Res., 99, 22,89722,914 .

Tegen, I., P. Hoorig, M. Chin, I. Fung, D. Jacob, and J. Penner (1997), Contribution of different aerosol species to the global aerosol extinction optical thickness: Estimates from model results, J. Geophys. Res., 102, 23,895-23,915.

Temperton, C., M. Hortal, and A. Simmons (2001), A two-time-level semiLagrangian global spectral model, Q. J. R. Meteorol. Soc., 127, 111-127.

Textor, C., et al. (2006), Analysis and quantification of the diversities of aerosol life cycles within AeroCom, Atmos. Chem. Phys., 6, 1777-1813.

Textor, C., et al. (2007), The effect of harmonized emissions on aerosol properties in global models: An AeroCom experiment, Atmos. Chem. Phys., 7, 4489-4501.

Tompkins, A. M. (2005), A revised cloud scheme to reduce the sensitivity to vertical resolution, Tech. Memo. 0599, 25 pp., Res. Dep., Eur. Cent. for Medium-Range Weather Forecasts, Reading, U. K.

Tompkins, A. M., C. Cardinali, J.-J. Morcrette, and M. Rodwell (2005), Influence of aerosol climatology on forecasts of the African Easterly Jet, Geophys. Res. Lett., 32, L10801, doi:10.1029/2004GL022189.

Vignati, E., G. de Leeuw, and R. Berkowicz (2001), Modeling coastal aerosol transport and effects of surf-produced aerosols on processes in the maritime atmospheric boundary layer, J. Geophys. Res., 106, 20,225-20,238.

Wisely, M. L., and B. B. Hicks (2000), A review of the current status of knowledge on dry deposition, Atmos. Environ., 34, 2261-2282.

P. Bechtold, A. Beljaars, A. Benedetti, A. Bonet, L. Jones, J. W. Kaiser, J.-J. Morcrette, M. Razinger, D. Salmond, S. Serrar, A. J. Simmons, M. Suttie, and A. Untch, European Centre for Medium-Range Weather Forecasts, Shinfield Park, Reading RG2 9AX, UK. (jean-jacques.morcrette@ ecmwf.int)

O. Boucher, Met Office, Hadley Centre, FitzRoy Road, Exeter EX1 3PB, UK.

M. Schulz, Laboratoire des Sciences du Climat et de 1'Environnement, L'Orme des Merisiers, F-91191 Gif-sur-Yvette, France.

M. Sofiev, Air Quality Research, Finnish Meteorological Institute, FIN-00560 Helsinki, Finland.

A. M. Tompkins, Earth System Physics, International Centre for Theoretical Physics, Strada Costiera 11, I-34014 Trieste, Italy. 